\title{
El Tratado de Límites de 1750 y el ocaso de la acción jesuítica en la Orinoquia
}

The Tratado de Límites of 1750

and the decline of Jesuit action in Orinoquia

José del Rey Fajardo SJ*

\section{Resumen.}

El presente artículo analiza el ocaso de la acción jesuítica en las regiones sureñas venezolanas a partir de la llegada de la Expedición de Límites de 1750. En una primera parte se estudia el contexto internacional en que se desarrolló el proceso previo desde el ángulo de las relaciones gobierno español y las autoridades ignacianas y los problemas creados con las Reducciones del Paraguay y las del Orinoco. En la segunda parte se aducen los contextos necesarios como las fuentes y sus protagonistas. En este sentido se lleva a cabo un arqueo de fuentes tanto de las inéditas producidas por los ignacianos sobre el tema así como también de las oficiales. La tercera parte entra de lleno en el tema e insiste en dos claves fundamentales. Una, la abierta animadversión de los Comisarios españoles hacia la "inercia de siglos" generada por las misiones; otra, el retiro de los jesuitas de las zonas limítrofes de Brasil, a petición del ministro Pombal, y el enfrentamiento entre jesuitas y capuchinos que acabó con la presencia de los hombres de Loyola en esas regiones y su expulsión definitiva en 1767 con sus lamentables consecuencias.

Palabras claves: Compañía de Jesús. Expedición de Límites de 1750. Ocaso de las Misiones del Orinoco. Amazonas y Orinoco.

\section{Abstract.}

This article analyzes the decline of Jesuit action in Venezuelan southern regions from the arrival of the Expedition of 1750 Limits In the first part the international context in which the previous process was developed from the perspective of relations is studied Ignatian Spanish government authorities and the problems created with the Reductions of Paraguay and the Orinoco. In the second part the necessary settings such as fonts and

\footnotetext{
* Academia Nacional de la Historia. Caracas.
} 
their protagonists argue. In this sense performs a calibration of both unpublished sources produced by the Ignatian on the subject as well as the officers. The third falls squarely on the issue and insists on two fundamental keys. One, the open hostility of the Spanish Commissioners to the "inertia of centuries" generated by the missions; another, the withdrawal of the Jesuits in areas bordering Brazil, at the request of the minister Pombal, and the confrontation between Jesuits and Capuchins that ended the presence of men of Loyola in these regions and their final expulsion in 1767 with its unfortunate consequences.

Key words: Society of Jesus; Boundary Expedition 1750; Sunset Mission del Orinoco; Amazon and Orinoco.

Recibido: 10 de setiembre de 2014

Evaluado: 28 de octubre de 2014 


\section{Introducción}

La Amazonia y la Orinoquia fueron un punto constante de meditación para las relaciones de Brasil con Paraguay, Perú, Quito y Nueva Granada. Y en el caso concreto de la Compañía de Jesús acabaría por adoptar el criterio de convertirse en un auténtico antemural frente a la penetración brasilera en tierras de la monarquía hispana.

Así lo demuestra la geografía histórica de nuestro subcontinente que propuso el cinturón de misiones de los seguidores de Ignacio de Loyola que se iniciaba en el alto Orinoco y pasaba por Mainas, Mojos, Chiquitos y el Paraguay ${ }^{1}$ y el cual significaba un bloqueo y una tentación para el avance portugués siempre ajeno al espíritu de Tordesillas ${ }^{2}$ Fig. 1.

En el presente trabajo estudiaremos únicamente el proceso seguido por las Misiones jesuíticas del río Orinoco tras la llegada de los miembros de la Expedición de Límites en las difíciles geografías entre los años 1754 y $1761^{3}$.

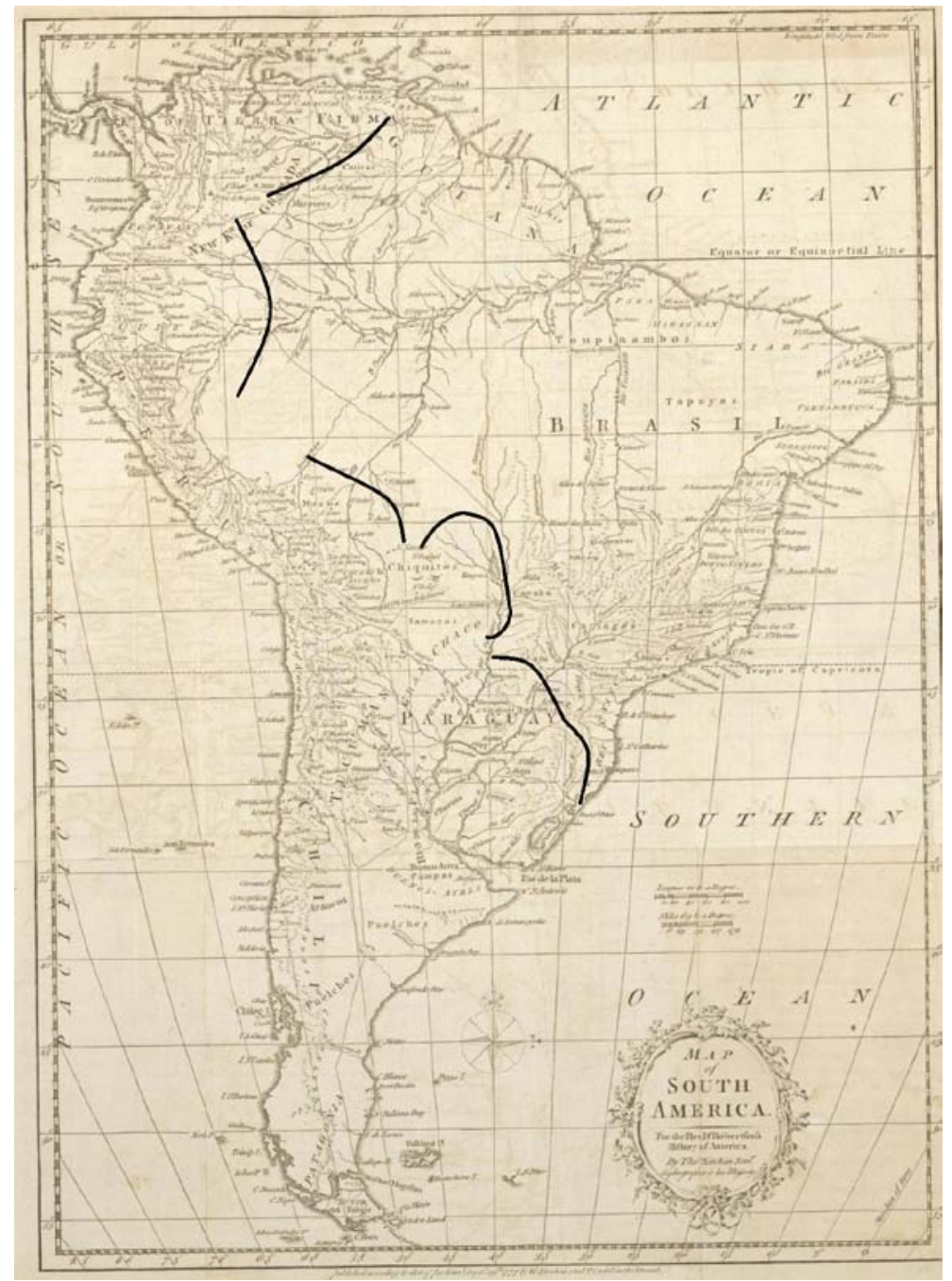

Fig. 1 Thomas Kitchin (1777). Map of South America para la Historia de América (1784) del Dr. Robertson's. señalando el cinturón de misiones.

\footnotetext{
${ }^{1}$ Para una información sistemática, véase: Santos Hernández, 1992: 34-56; 65-83.

2 Barandiarán, 1992, T, II: 129-360 y 209-265.

${ }^{3}$ Lucena Girardo, 1997a, T. II: 292-294 y 1992-1993: 243-257.
} 
Tras largas y secretas conversaciones entre España y Portugal se llegó al Tratado firmado en Madrid a 13 de enero de 1750 para determinar los límites de los Estados pertenecientes a las coronas de España y Portugal en Asia y América ${ }^{4}$.

En última instancia se trataba de diseñar una división de la América del Sur bajo dos áreas de influencia: la del Amazonas para Portugal ${ }^{5}$ y la del Río de la Plata para España.

Pero si nos restringimos al tema jesuítico debemos clarificar que en esas mismas fechas se dirigía el P. Francisco Retz $(1673-1750)^{6}$, General de la Compañía de Jesús, a sus súbditos del Paraguay para que cumplieran con lo estipulado en el Tratado ${ }^{7}$. El gobierno español había solicitado al P. General, por medio del confesor real P. Francisco Rábago ${ }^{8}$, que tomara las medidas necesarias a fin que los misioneros del Paraguay colaboraran a la evacuación de las siete reducciones canjeadas por la Colonia del Sacramento ${ }^{9}$.

Mas el 9 de noviembre de ese año fallecía el P. Retz y el 4 de julio de 1751 era elegido para sustituirle el P. Ignacio Visconti (1682-1755) ${ }^{10}$. Diez y siete días más tarde le escribía el nuevo General a los Provinciales del Paraguay, Perú, Quito y al Superior de la misión una carta explicativa de su posición ${ }^{11}$.

Fundamentaba el General de la Orden su mandato en dos razones para él poderosas. Primera, que muchos de los más poderosos de Francia, Inglaterra, Holanda, Portugal y España han impresionado a la corona de Portugal "que son tan gruesos los tesoros y comercio que tienen los jesuitas en aquellas partes del Paraguay, que no entregarán los siete pueblos de indios Guaraníes como no sea por fuerza de las armas". Segunda, era tal la presión internacional que se llegó a pedir que el tratado se ratificara sólo cuando en uno de sus artículos quedase expresado con toda claridad el temor de ambas colonias a que los jesuitas aceptaran tal disposición e incluso se fijara el mutuo compromiso de obligar a los misioneros a la evacuación de los pueblos por las armas si fuera necesario. Como el Rey de España no aceptó tal proposición tan denigrativa para la Compañía de Jesús, salió el monarca garante de la Orden y empeñó su real palabra en nombre de los jesuitas ${ }^{12}$.

\footnotetext{
${ }^{4}$ Calvo, 1862: 244 y ss. Astraín, 1925: 640. Según el autor el documento se encuentra en AGI. 124-4-9. A fin de no multiplicar la información bibliográfica nos remitimos a Caraman y Baptista, 2001, T. I: 139144.

${ }^{5}$ BPM. Manuscritos, 2852. “Testamento político” por José de Carvajal. Elliot, 2006.

${ }^{6}$ Mellinatto, 2001, T.II: 1653-1654.

${ }^{7}$ Astraín, 1925: 644.

${ }^{8}$ Alcaraz Gómez, 1995.

${ }^{9}$ AGS. Estado, 7387, fol., 32. Carta del P. Rábago al P. Barreda. Madrid, 1 de febrero de 1753: "Lo segundo que no pude escusar, fué escribir a nuestro Padre General, que facilitase la ejecución de un tratado que el Rey había hecho, creyéndole conveniente; en lo que hice lo que me mandaron; y lo que nuestro Padre no podía negar, debiendo suponer que cada uno sabe lo que le importa; y que no había inconveniente en la ejecución". Citado por Kratz, 1954: 45.

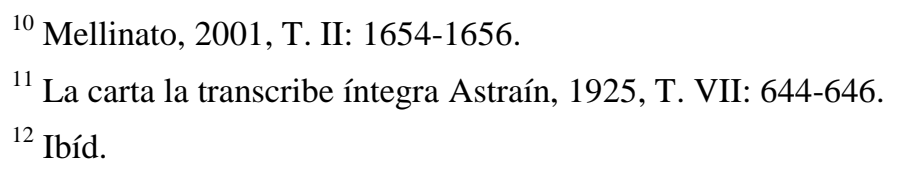


Sin embargo, bajo estas aparentes y normales decisiones de la alta dirigencia política española y de la espiritual romana se movían corrientes tormentosas que pronto irrumpirían en el panorama internacional con sus temibles consecuencias.

En primer lugar se ponía a prueba una vez más la teoría de la libertad defendida por los jesuitas desde Francisco Suárez $(1548-1617)^{13}$ pues la realidad iba a demostrar que el proceso no era tan fácil y los misioneros se negaron a aceptar las imposiciones de Roma. Y así redactaron su Representación que los Padres Curas y compañeros de las doctrinas hacen al Confesor del Rey Fernando VI, Padre Francisco Rábago, sobre los cargos de conciencia que resultan a Su Majestad en la ejecución del tratado del 1750 entre España y Portugal en la que fijan su posición y concluyen:

"De todo lo cual se sigue legítimamente, que no es lícito llevar los indios guaraníes de sus siete pueblos a otras tierras, ni desposeerlos de sus tierras y bienes raíces, ni enseñar o decir, que tal se puede hacer en conciencia. Luego no es fácil concordar la ejecución del real tratado con la debida observancia de tan sagrados decretos. Luego no es materia ésta, en que nuestra conciencia está segura del acierto, obedeciendo a una ley civil y humana, a que tan claramente contradicen la ley natural, la divina, la eclesiástica y la civil ${ }^{14}$.

También algunos Profesores de la Universidad de Córdoba defendían ser nulas las cláusulas del tratado, referentes a este punto y, por consiguiente, sin vigor la orden del P. General de la Compañía de Jesús ${ }^{15}$.

Este enfrentamiento entre un mandato de la obediencia y la imposibilidad de su cumplimiento, (y en el caso específico de la república guaranítica, los derechos humanos de los indígenas se erigían como una genuina objeción de conciencia), no era nuevo en la Orden religiosa de Ignacio de Loyola. En sus grandes luchas por la libertad y por la búsqueda de una empatía en pro de la aceptación de la alteridad, los jesuitas habían librado batallas trascendentales.

Sobre los planos del espíritu crítico, de la episteme universal y de la lógica científica edificaría Mateo Ricci (1552-1610) ${ }^{16}$ "los ritos chinos" y esta imponente arquitectura de la "otredad" sería arrasada como una síntesis de lo imposible ${ }^{17}$. Análogo periplo recorrería Roberto Nóbili (1577-1656) ${ }^{18}$ con "los ritos malabares" en la India y sus huellas quedan vigentes en la historia de las ideas y de las creencias.

El dramaturgo judío Fritz Hochwälder plantea como tesis los aplazamientos del Reino de Dios en la Tierra en su controversial pieza teatral Das heilige Experiment ${ }^{19}$. El fin de la utopía nunca puede ser previsto. El núcleo del escritor vienés gira en torno al establecimiento de la justicia y la paz en la tierra. Y establece que "La verdad y la paz no son nada si no se encarnan; pero, tan pronto como lo hacen, se ven perseguidas y tienen que refugiarse en el desierto. El hombre aspira sin cesar al reinado de la justicia,

\footnotetext{
${ }^{13}$ Elouduy, 2001, T. IV: 3654-3656.

${ }^{14}$ AHN. Jesuitas, 120. Astraín, T. VII: 650-651.

${ }^{15}$ Carta del P. Escandón al P. Robles. Buenos Aires, 21 de marzo de 1765. En: Kratz, 1954: 61.

${ }^{16}$ Sebes, 2001, T. IV: 3351-3353.

${ }^{17}$ Lacoutuere, 1993: 331-400.

${ }^{18}$ Ponnad, 2001, T. II: 1059-1061.

${ }^{19}$ Das heilige Experiment. Zurich, 1941. Sur la terre comme au ciel. París, 1952. Maliá, 1967: 622-628.
} 
pero desde el momento en que éste se perfila en el horizonte, tiene que sacar la espada para defenderlo; entonces la mística, al convertirse en política, se degrada y reniega de sí misma"20.

En esta oportunidad al conflicto de conciencia interno dentro de la disciplina de la Orden fundada por Ignacio de Loyola se añadía en el horizonte político el malestar de una atormentada política internacional del mundo europeo sobre la América hispana ${ }^{21}$.

En síntesis, el Tratado de Límites de 1750 presagiaba días difíciles para los jesuitas de América que concluiría el año de 1767 con la expulsión de los dominios del rey de España y desataría nuevas tormentas para la etapa independentista.

Con estos antecedentes accedemos a nuestro tema de estudio que se circunscribe a las geografías que se ubican al norte del río Amazonas y al ocaso de la actuación de los jesuitas neogranadinos en estas desiertas soledades.

Si las tierras sureñas la Colonia de Sacramento centraban las apetencias portuguesas, al norte del río Amazonas la estrategia expansionista lusitana también había ejercido una lenta pero meditada conquista del territorio.

Sin lugar a dudas el macizo guayanés y sus fronteras con las naciones que bordeaban su geografía se mantuvo en tiempos coloniales en continuo vaivén, pues eran tierras abiertas continuamente al riesgo y a la aventura.

Por una parte, las grandes superficies comprendidas entre los límites con Brasil y la baja Orinoquia se convirtieron en un territorio de nadie donde se practicaba un comercio de urgencia y de necesidad, se canalizaba la exportación prohibida y se permitía la inmigración y emigración clandestinas, sobre todo, cristianos nuevos, inculpados por la Inquisición, perseguidos por la justicia, mano de obra esclava indígena y negra y comerciantes españoles, portugueses y extranjeros ${ }^{22}$.

Por otro lado, la historia de la Provincia de Guayana ${ }^{23}$ comienza a dejar sentir su peso histórico definitivo a lo largo del siglo XVIII.

Entre los años 1700 y 1736, los capuchinos aragoneses que laboraban en la Provincia de Cumaná, sita al norte del Orinoco, habían orientado sus esfuerzos para colonizar el río Guarapiche dominio de los caribes y centro de intercambio con los miembros de su raza de las islas caribeñas.

Las acciones del gobernador José Francisco Carreño ${ }^{24}$ obligarían a los representantes de esta etnia a retirarse a la obra banda del Orinoco ${ }^{25}$, es decir, a las regiones de Puruey y Caura desde donde se federaron, sin dificultades geográficas, con sus hermanos de raza que habitaban la gran región de Barima, Aquire y Esequivo y de esta suerte fortalecieron la "Gran Caribaria”.

\footnotetext{
${ }^{20}$ Moeller, 1958: 516.

${ }^{21}$ Una síntesis puede verse en: Alcaraz Gómez, 1995: 666-696.

${ }^{22}$ Boxer, 1953, IV: 195-212.

${ }^{23}$ Una síntesis en: García Castro, 1997: 594-597.

24 Pérez, 1997: 699.

${ }^{25}$ Carrocera, 1979: 17-22.
} 
Pero, despejado el peligro en la zona norte del Orinoco se creaban dos entidades autónomas en la zona sur: el núcleo del Bajo Orinoco (Barima-Sierra Imataca con el río Aquire y Cuyuni) y el núcleo del Orinoco medio (ríos Aro, Caura y área del Puruey hasta cerca del Cuchivero) ${ }^{26}$ Fig. 2.

A ello hay que añadir la trágica realidad que vivía la Provincia de Guayana. La inmolación étnica del libre imperio caribe ${ }^{27}$ en el Orinoco "puede fácilmente calcularse en más de 30 mil indios aniquilados y más de diez mil vendidos como esclavos por los caribes, con la complicidad de los holandeses, franceses, ingleses y hasta de los mismos españoles. ¡Cuarenta mil víctimas en solo la hidrografía del Orinoco, en solo 30 años (1696-1730) sin contar los doce años de la hecatombe que representó el episodio de Quirawera (1684 a 1696)”. Y concluye Barandiarán: “Todo era desolación, esclavitud y muerte" ${ }^{28}$.

En este contexto se debe ubicar la acción jesuítica en la gran Orinoquia. Habiendo regresado al gran río venezolano "por noviembre de $1731^{29}$ vivirían durante el espacio temporal comprendido entre 1733 y $1744^{30}$ la historia más sangrienta de esa

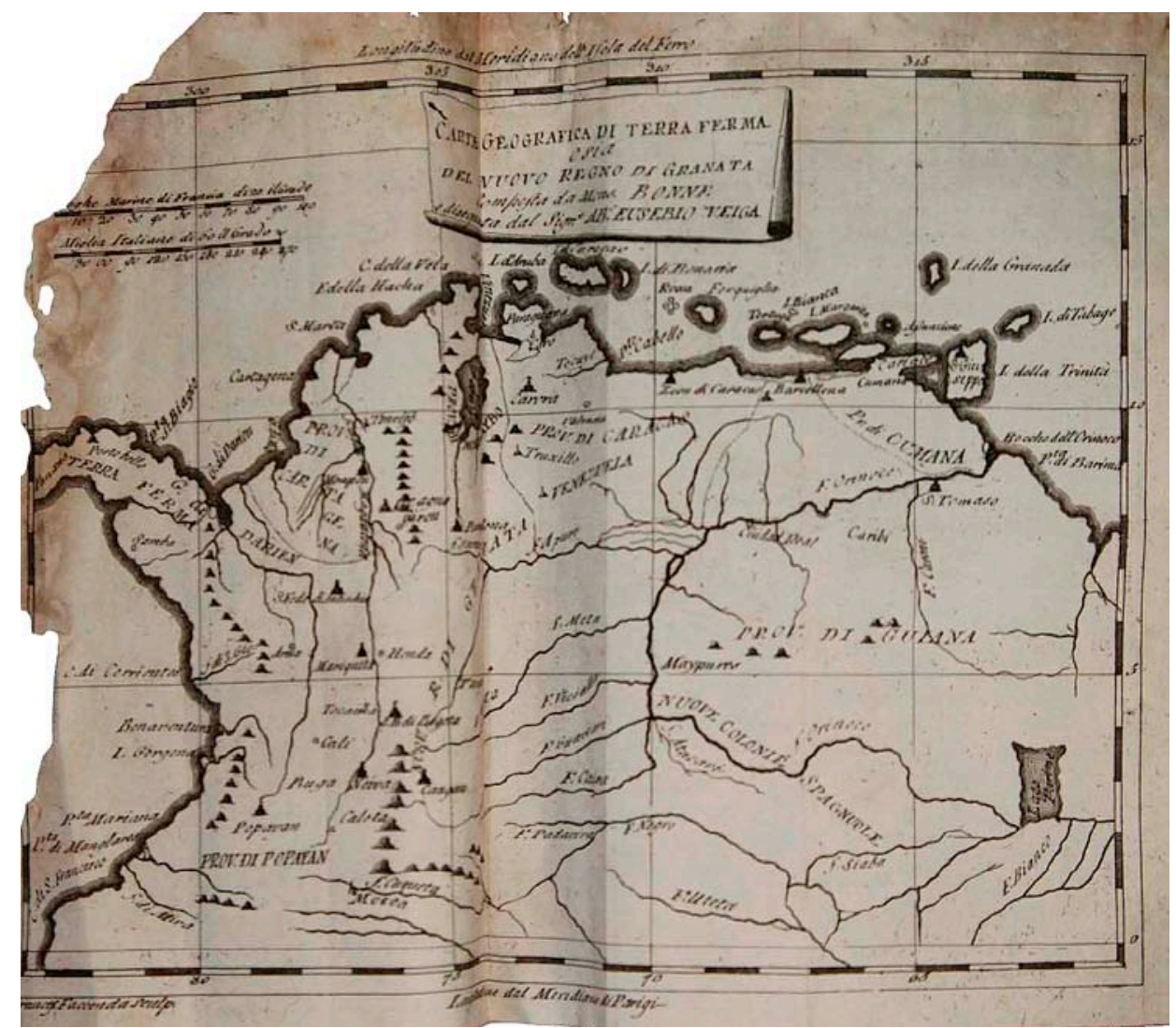

Fig. 2. Carta geografica di Terra Ferma osia del nuovo regno di Granata composta da mons. Bonne e disegnata dal sig.re Al. Eusebio Veiga. En: Gilii. 1965.

\footnotetext{
${ }^{26}$ Barandiarán, 1992: 241.

${ }^{27}$ Sobre los caribes: Del Rey Fajardo, 2011, T. IV: 414-440.

${ }^{28}$ Barandiarán, 1992: 237-241. Ramos Pérez, 1988: 241.

29 AGI. Caracas, 391. Carta de Gumilla al Gobernador Sucre. Orinoco, febrero 23 de 1733. Sin embargo, Cassani, 1967: 397 pone como fecha de ingreso el 10 de diciembre de 1731.

30 Vega 2000: 26: "... por marzo de 733, quedo rota la guerra con la Nacion Cariba que nos dieron bastante que hacer hasta el año de 744".
} 
macro zona del siglo XVIII en donde, en definitiva, el Estado español se declaraba, de facto, incompetente para frenar la gran ofensiva protagonizada por la confederación de una serie de naciones bárbaras, vigorizadas por el apoyo holandés y francés.

La historia documentada de la guerra declarada por la nación caribe en 1733 contra las misiones jesuíticas puede verse en la crónica que escribió un testigo presencial: el Hermano Coadjutor jesuita llamado Agustín de Vega ${ }^{31}$.

El estudioso de este fenómeno orinoquense llega a la conclusión de que en épocas de crisis, la paz se compra o se pretende instaurar al margen de la justicia y de esta forma las invasiones caribes de 1733 hay que verlas a la luz de esta realidad. De esta forma la seguridad jurídica y política de las gentes del Orinoco quedaba viciada y la impotencia obligaba al misionero a apelar a acciones desesperadas.

¿Cuál fue la respuesta de la Compañía de Jesús a las múltiples formas de acción y penetración que desarrollaría la nación caribe en los escenarios sitos entre Cabruta ${ }^{32}$ y el Raudal de Atures ${ }^{33}$ ?.

Con los pueblos destruidos, las diversas etnias indígenas misionadas, dispersas y atemorizadas, los jesuitas comenzaron a tomar sus propias decisiones a fin de afrontar la crisis que ponía una vez más entre la espada y la pared el futuro misional y por ende territorial de la corona española en la Orinoquia.

La primera fue levantar un fortín en Marimarota ${ }^{34}$, monte todo de roca, situado en las cercanías de Pararuma ${ }^{35}$. Se trataba de un lugar estratégico donde el río "se estrecha como a un tiro de fusil”" ${ }^{36}$. De seguidas establecieron los mecanismos de defensa y enfrente levantaron una especie de fortín de forma tal que el fuerte se dotó de cañones y el pueblo de "estacadas" ${ }^{37}$. El P. Gilij describe el entorno así: "Es terrible el trozo de río entre el Castillo y Carichana por los muchos escollos que se pasan”38. La construcción del reducto de San Javier en Marimarota trajo tranquilidad durante el año 1736 pues este primitivo puesto militar consiguió impedir el flujo de las armadas caribes aguas arriba ${ }^{39}$.

La segunda se inicia en 1740 con la fundación de Cabruta ${ }^{40}$. Su valor estratégico sería reconocido a posteriori. Sin lugar a dudas, tras el fortín de San Javier, supone el segundo gran antemural que levantaron los jesuitas en su lucha con los caribes. En este punto la visión de Bernardo Rotella (1700-1748) ${ }^{41}$ fue mucho más intuitiva que la de

\footnotetext{
31 Ibíd.

${ }^{32}$ Del Rey Fajardo, 2007-2011, T. III: 80-82.

33 Ibíd.: 35-37.

${ }^{34}$ Ibíd.: 198-201.

${ }^{35}$ Ibíd., 1996: 61-62.

${ }^{36}$ Gumilla, 1993: 202.

${ }^{37}$ Vega: 76-77: Y anota con cierta complacencia el H. Vega: "Con esto cobró tan gran fama el Castillo de San Xavier que no se hablaba de otra cosa en todo Orinoco sino del Castillo".

${ }^{38}$ Gilij, 1965, T. I: 40.

39 AGI. Quito, 198. Segunda Vía. Respuesta al pliego... 1742. (Gumilla, 1970: 307).

${ }^{40}$ Del Rey Fajardo, 2007-2011, T. III: 80-82.

${ }^{41}$ Ibíd., 2006: 605-607.
} 
Manuel Román (1696-1766) ${ }^{42}$, que era el Superior de la misión del Orinoco en aquel entonces.

El corrimiento de la frontera jesuítica a Cabruta y su ubicación en un punto geográfico vital como antemural para contener las fuerzas caribes ${ }^{43}$ abre un nuevo ciclo en la intercomunicación con la Provincia de Caracas y en la toma de conciencia de los jesuitas orinoquenses de buscar en la ciudad del Ávila su nueva capital. Pero, además, se erigía como un privilegiado lugar de encuentro de muchos pueblos del gran río venezolano en busca de subsistencia y mercadeo y sobre todo por el valor del mercado de la tortuga ${ }^{44}$.

La polémica fundación de Cabruta obligó a los caribes a reformular de nuevo sus rutas esclavistas y a refinar sus técnicas de dominio y terror entre los conglomerados indígenas acogidos a la vida misional. Por una parte mataban o secuestraban a los indios reducidos cuando los encontraban desguarnecidos en los contornos de los poblados o en despoblado; y por otra les hacían llegar su criterio de que si no emigraban a las tierras caribes regresarían para matarlos y destruir los enclaves misionales. Tal fue su modo de actuar a lo largo de los años 1740 y $1741^{45}$.

La tercera respuesta sería inédita e inesperada. Lo que no pudieron conseguir ni los gobernadores ni los misioneros lo obtendrían los nuevos aliados indígenas de los jesuitas. En efecto, serían los cabres $^{46}$ y sobre todos los guaypunabis ${ }^{47}$ quienes acabarían de raíz la hegemonía caribe en el Orinoco medio. Felipe Salvador Gilij (17211789) ${ }^{48}$, que llegó al Orinoco en 1749 , debía recordar muy vivamente las historias misioneras como ya superadas, pues escribiría en su Ensayo de Historia Americana que Puruey "ahora es a modo de quemada Troya humeante memoria de sus triunfos sobre las naciones orinoquenses, si dejando a los valerosos se hubieran contentado con subyugar a los más débiles" ${ }^{49}$.

\section{Los contextos orinoquenses a la llegada de la expedición de límites a Venezuela}

\section{Las fuentes y sus protagonistas.}

A fin de poder abrir posibles cauces al tema propuesto iniciaremos con un breve arqueo de las fuentes jesuíticas. Pretendemos establecer un acercamiento a las relaciones de los misioneros jesuitas orinoquenses y los comisarios regios en el espacio temporal más amplio como es el comprendido entre 1755 y 1767.

\footnotetext{
${ }^{42}$ Ibíd., 2006: 595-599.

${ }^{43}$ Gilij, I: 71, expresa: "Esta aldea que está en la frontera de los caribes, fue fundada por Rotella en 1740 con el designio de fortificarla lo más que pudiese contra los insultos de estos enemigos que entonces dominaban, y pensó en hacer de ella como un antemural fortísimo para defender también a las otras reducciones".

${ }^{44}$ Ramos, 1946: 154.

${ }^{45}$ AGI. Quito, 198. Doc. cit. (Gumilla. Escritos varios: 306).

${ }^{46}$ Del Rey Fajardo, 2007-2011, T. IV: 408-411.

${ }^{47}$ Ibíd.: 470-473.

${ }^{48}$ Ibíd., 2006: 311-316.

${ }^{49}$ Gilij, I: 62.
} 
Mas, antes de proceder a esbozar las fuentes jesuíticas propiamente tales nos permitimos sugerir al investigador, para la mejor comprensión de la tierra y el hombre de esas difíciles geografías, la utilización de nuestras publicaciones dedicadas tanto a los autóctonos ${ }^{50}$ como a la geografía histórica $^{51}$.

Y como pórtico señalamos los principales protagonistas de este tramo histórico. Fueron Superiores de la Misión: Roque Lubián (1755-1758) ${ }^{52}$; Manuel Román (1758$1761)^{53}$; Felipe Salvador Gilij (1761-1765) ${ }^{54}$; José María Forneri (1765-1767) ${ }^{55}$. A ellos habría que añadir los misioneros Bernardo Rotella (1700-1748) ${ }^{56}$ y Francisco del Olmo (1709-1765) ${ }^{57}$ así como también el Procurador de Indias en Madrid Jaime Torres (1711¿'? $)^{58}$.

Hasta el presente no hemos podido encontrar la documentación oficial que recoja las instrucciones y la correspondencia mantenida entre Roma y los Provinciales del Nuevo Reino de Granada durante esa importante década.

Nos llama la atención que uno de los escritos fundamentales de los misioneros como es el del P. Juan de Escandón (1696-1772) ${ }^{59}$ : Relación de los sucesos del Paraguay con motivo del tratado entre la Corte de España y Portugal ${ }^{60}$, fechado en Barcelona el 15 de febrero de 1760, esté dirigido al P. José Pagés (1709- ¿? $)^{61}$, Procurador de la Provincia del Nuevo Reino ${ }^{62}$. Este hecho nos lleva a presumir que también los jesuitas neogranadinos seguían de cerca los avatares de una tormenta que tan sólo estaba comenzando ${ }^{63}$.

En lo referente a Venezuela podemos decir que la documentación conocida no va mucho más allá de lo anecdótico. Y en lo relativo a los problemas de fondo podemos aseverar que hasta el presente no conocemos ningún escrito que afronte directamente el tema.

Sin embargo, es de vital importancia revisar el expediente que el Secretario del Consejo de Indias le remitió en diciembre de 1748 a don José de Carvajal sobre la frontera amazónica ${ }^{64}$.

\footnotetext{
${ }^{50}$ Del Rey Fajardo, 2007-2011, T. IV.

${ }^{51}$ Ibíd., T. III.

${ }^{52}$ Ibíd., 2006: 394-397.

${ }^{53}$ Ibíd.: 595-599.

${ }^{54}$ Ibíd.: 311-316.

55 Ibíd.: 290-293.

${ }^{56}$ Ibíd.: 605-607.

${ }^{57}$ Ibíd.: 515.

${ }^{58}$ Ibíd.: 700-703.

${ }^{59}$ McNaspy - Domínguez, “Escandón, Juan”, 2001, T. II: 1251-1252.

${ }^{60}$ Uriarte y Lencina, 1929-1930: 490 y ss.

${ }^{61}$ Del Rey Fajardo, 2006: 528-531.

${ }^{62}$ Kratz, 1954: 12.

63 Para la parte relativa a Quito nos remitimos a: Gómez González, 2014.

${ }^{64}$ AGI. Quito, 158. Expediente del Gran Pará.
} 
Dentro de la historiografía jesuítica se citan dos obras, todavía inéditas, para la biografía de la Orinoquia escritas por el P. Roque Lubián. Nos referimos a la Historia del Orinoco y al Apéndice a la Real Expedición de límites entre los dominios de España y Portugal en América.

Llegamos al conocimiento de ambos escritos gracias a la reseña que les otorga el bibliógrafo hispano Lorenzo Hervás y Panduro (1735-1809) ${ }^{65}$ en su Biblioteca jesuítico-española ${ }^{66}$. Sin embargo, conviene precisar algunas de sus afirmaciones. Dice Hervás que Lubián "dejó en América los siguientes manuscritos que tenía dispuestos para la impresión" 67 .

En realidad esta afirmación no creemos que se ajuste a los hechos. En los inventarios levantados en la reducción de San Miguel de Macuco (Misión del Meta) al momento del extrañamiento no aparecen tales manuscritos ${ }^{68}$ y si existieron no son los que en el destierro de Roma redactó el misionero orinoquense.

La hipótesis formulada -al menos para la Historia del Orinoco- tiene su confirmación en el testimonio del P. Antonio Julián (1722-1790) ${ }^{69}$, quien al respecto afirma desde su destierro italiano:

"Y para que no vacile el lector sobre la verdad de lo referido, concluyo con asegurar al público que todo cuanto he producido y queda dicho de los extranjeros en el Orinoco alto y bajo en estos dos discursos preliminares, todo lo he sacado de la historia del Orinoco, que en cuadernos manuscritos (que tengo en mi poder) dejó en la hora de su muerte a un amigo mío (nota: El señor don Manuel Balzátegui, sujeto de probada virtud, integridad y doctrina, que fue por muchos años superior y depositario de los santos designios de Lubián) el señor abate don Roque Lubián, antiguo misionero del Orinoco y Meta, en la que fue Provincia de Santa Fe; varón de probadísima virtud y sinceridad apostólica, honor del reino de Galicia y operario insigne en aquellas misiones por más de cuarenta años continuos; compañero e íntimo confidente del famoso padre Manuel Román, de cuya boca también hemos oído, muchos que al presente vivimos, estos mismos y semejantes trágicos sucesos" ${ }^{70}$.

Ciertamente que esta redacción no fue hecha en suelo americano sino que pertenece ya a la época del destierro. Hasta el momento no hemos logrado obtener noticia alguna del paradero de los "cuadernos manuscritos" que vendrían a clarificar una zona temporal, todavía no escrita, sobre la acción jesuítica en el gran río venezolano.

Otra vertiente, relativamente explorada, está constituida por la correspondencia y los informes de los miembros de la Expedición que directamente tuvieron que ver con los jesuitas ${ }^{71}$.

\footnotetext{
${ }^{65}$ De la Camoa, 2001, T. II: 1914-1916.

${ }^{66}$ Hervás y Panduro, 2007: 343-344.

${ }^{67}$ Ibíd.: 344.

${ }^{68} \mathrm{El}$ inventario reposa en: ANB. Conventos, t. 34, fols., 805-808.

${ }^{69}$ Del Rey Fajardo, 2006: 595-599, 363-369.

70 Julián, 1951: 168-169. [El subrayado es nuestro].

${ }^{71}$ Haremos referencias concretas a lo largo del artículo.
} 
En el campo oficial nos centramos de forma preferente en los tres primeros Comisarios: José de Iturriaga (1699-1767) ${ }^{72}$, Eugenio de Alvarado (1715-1767) ${ }^{73}$ y José Solano $(1726-1806)^{74}$.

La corriente española podemos afirmar que se abre con la tesis doctoral del infatigable profesor vallisoletano, D. Demetrio $\operatorname{Ramos}^{75}$ y se completa con la ingente obra del investigador Manuel Lucena Giraldo ${ }^{76}$.

Sin lugar a dudas podemos afirmar que Lucena Giraldo se ha convertido en el más cualificado especialista sobre el complejo ámbito histórico que supone el Tratado de Límites de 1750. Sin embargo, un decisivo aporte al Tratado de Límites y su entorno ha sido la publicación de su libro Viajes a la Guayana ilustrada ${ }^{77}$.

Pero en el caso específico de la Compañía de Jesús neogranadina el mejor aporte lo ofrece el Informe reservado ${ }^{78}$ del coronel don Eugenio de Alvarado (1756) quien años después desplegaría en Madrid una activa intervención junto al Conde de Aranda en la búsqueda de causas o razones que pudieran justificar la expulsión de los jesuitas de los dominios españoles. El primer comisario, don José de Iturriaga, una vez llegada al Orinoco medio la Expedición, encargó a Alvarado, en una instrucción del 29 de febrero de 1756, que se informara en secreto de todo lo que acontecía en la misión de Carichana $^{79}$ y en febrero de 1757 había concluido el segundo comisario su escrito que no es otro que el Informe reservado ${ }^{80}$.

El Informe está claramente redactado en dos etapas: la primera, en las misiones entre 1756 y comienzos de 1757; la segunda, en Madrid, hacia 1766, cuando el Estado hispano buscaba desesperadamente argumentos que justificaran la expulsión de la Orden de Ignacio de Loyola. Con todo, su carácter intrigante y trepador, que queda ampliamente demostrado tanto en el Informe como en la correspondencia que de él conocemos a través de la documentación reproducida por Antonio B. Cuervo ${ }^{81}$ obliga a tomar el documento con mucha cautela, sobre todo cuando emite juicios de valor sobre los jesuitas y sus acciones.

\footnotetext{
${ }^{72}$ Para su biografía: Lucena Giraldo, 1991c: 105-107 y 1997: 831-832.

${ }^{73}$ Ibíd.: 107-108. Ramos Pérez, 1997: 130-131.

${ }^{74}$ Ibíd.: 109-110. Parra Pardi, 1997: 1173-1174.

75 Ramos, 1946. Demetrio Ramos ha sido un excelente colaborador en la reconstrucción de la historia colonial venezolana y su obra es amplísima.

${ }^{76}$ Lucena Giraldo, 1991c. A Lucena Giraldo se le puede considerar como el renovador de la literatura ilustrada de la frontera. Tiene diversas obras de las que solamente agregamos 1988.

${ }^{77}$ Ibíd., 1999.

${ }^{78}$ Alvarado, 1893.

79 AGS. Estado, 7396, fol., 40. Citado por Ramos Pérez, 1946: 223: "Durante la residencia de V. S. en Carichana se informará reservadam[en]te del Govierno interior de la Mision. De sus progresos en la reduz[ió]n de Infieles de las Naciones en que pueden executarla; del número y calidad de la gente; terreno y distancia de cada una; del número y Vecindario de sus Pueblos, con distinción de los que no fuer[a]n Yndios; del modo de tratar a unos y a otros en lo que los emplean y en que año fueron fundados: de las Haciendas y Grangerías que tenga la Misión; del Ministerio y y exercicio del Procur[a]dor que suele residir en Carichana, y de la Escolta su número, calidad y paga efectiva". Según el testimonio del propio Alvarado este Informe lo tenía concluído "desde Febrero de 57" (AGS. Estado, 7396, fol., 40).

${ }^{80}$ AGS. Estado, 7396, fol., 40.

${ }^{81}$ Cuervo, 1893: 111-225.
} 
En el juego de intereses de los comisionados opina Demetrio Ramos que Iturriaga se sirvió de Alvarado para tratar con los jesuitas a la vez que lo utilizó para que acaparara sobre si toda la enemistad de los miembros de la Compañía de Jesús ${ }^{82}$. Por su parte, el hijo de Barbocoas, en su correspondencia intrigante, llega a afirmar que tanto Iturriaga como Solano se habían confabulado con los jesuitas para que no avanzara la Expedición ${ }^{83}$.

Por ello no resulta fácil la lectura y comprensión de la correspondencia de Alvarado, pues su obligado ocio en Carichana así como su probado antijesuitismo le abrieron espacios idóneos para todo tipo de maquinaciones, razón por la cual le obliga al historiador a someter a mayor crítica lo suspicaz de sus apreciaciones.

Finalmente, dentro de la historiografía revisionista venezolana ha habido una toma de posición crítica que encabeza el antropólogo e historiador Daniel de Barandiarán quien ha sometido a la luz de la historia y la geografía guayanesas todo el inmenso acervo producido por la Expedición de Límites de 1750 y a su obra remitimos nuestras observaciones ${ }^{84}$. Desde el ángulo jesuítico nos remitimos a nuestra obra Las Misiones germen de la nacionalidad ${ }^{85}$.

\section{La situación de la Provincia de Guayana hacia 1750.}

La década que corre entre 1740 y 1750 fue clave para comenzar de veras a la pacificación de la Orinoquia.

A nuestro juicio, cuatro grandes acontecimientos cambiarían la visión y las estrategias misionales en el gran río venezolano: 1) la publicación en Madrid, en 1741, El Orinoco ilustrado escrito por el P. José Gumilla; 2) el descubrimiento del brazo Casiquiare por el P. Manuel Román $(1744)^{86}$; 3) el mapa de Bernardo Rotella (1747) que hoy es el primer testimonio gráfico del Orinoco guayanés y no andino ${ }^{87}$; 4) y el extermino caribe en la zona media del Orinoco gracias a los guaypunabis traídos por el P. Manuel Román desde el alto Orinoco en 1746.

En 1741 aparecían en la capital hispana dos obras fundamentales para el conocimiento histórico de la Orinoquia: la Historia de la Provincia de la Compañía de Jesús del Nuevo Reino de Granada, en la América ${ }^{88}$ del cofundador de la Real Academia José Cassani (1673-1750) ${ }^{89}$ y mencionado El Orinoco ilustrado ${ }^{90}$ del misionero del gran río venezolano, P. José Gumilla (1686-1750) ${ }^{91}$.

\footnotetext{
${ }^{82}$ Ramos Pérez, 1946: 224.

${ }^{83}$ Cuervo, 1893, T. III: 501.

${ }^{84}$ Barandiarán, 1994: 331-774.

${ }^{85}$ Del Rey Fajardo, 2007: 259-292. Lucena Giraldo, 1992-1993: 243-257.

${ }^{86}$ AIUL. Papeletas: Román, Manuel. "Descubrimiento de la comunicación del Orinoco con el Marañón y Relación que hace el P. Manuel Román de su viaje de Carichana al Río Negro: desde el 4 de febrero hasta el 15 de octubre de 1744".

87 MNM. Manuscrito, 320. Allí reposan tanto el "Mapa de Guayana” como las "Noticias sobre la geografía de la Guayana”. Caicara, abril primero, año de 1747.

${ }^{88}$ Cassani, 1741.

${ }^{89}$ Martínez de la Escalera, 2001: 695.
} 
Así pues, no es de extrañar que la biografía gumillana del río Orinoco, tutelada por el aval de tan ilustre académico, tuviera pronto una enorme repercusión en el mundo europeo. Para citar tan sólo un ejemplo ilustrativo: en los tres lustros que separan la segunda edición (1745) de El Orinoco ilustrado y defendido del año 1760, aparecieron en Francia extensas síntesis y estudios que venían a hacerse eco de la problemática planteada por la curiosa sagacidad del misionero jesuita ${ }^{92}$.

Pero mientras José Gumilla publicaba en Madrid su obra de forma acelerada se iba tratando entre sus conmilitones de trazar la nueva frontera que se extendía hasta el río Amazonas.

El 12 de abril de 1742 el Superior de las Misiones del Orinoco, P. Manuel Román, comunicaba por vez primera al Monarca español la existencia del curioso fenómeno geográfico basado en las noticias que le habían dado algunos portugueses que fueron a parar en las misiones jesuíticas. Y concluía: "esta noticia no tiene en si más verdad que la que se puede dar a dichos viajeros"

El 14 de enero de 1744 decide el P. Manuel Román realizar su viaje hacia el sur a fin de verificar personalmente el enigma del brazo Casiquiare que aclaraba la intercomunicación fluvial del Orinoco con el Amazonas ${ }^{94}$.

\footnotetext{
${ }^{90}$ Gumilla, 1993.

${ }^{91}$ Del Rey Fajardo, 2006: 338-347.

92 Mémoires pour I'Histoire des Sciences et des beaux Arts, commencés d'etre imprimés l'an 1701 a Trevoux et dédiés a son Altesse Sérénissime Monseigneur le Prince Souverain de Dombes.
}

A Paris. Chez Chabert:

- (1747) Oct. Dec., pp. 2.319-2.345,2.501-2.524.

- (1748) Jan. Mar., pp. 27-53, 189-191.

- (1759) Mar.-Avril, PP. 623-640.

Année Littéraire, année M.DCC.LVIII par M. Fréron, des Académis d'Angers, Montauban, de Nancy, de Marseille et de Caen.

A Amsterdam. Et se trouve a Paris chez Michel Lambert.

- (1758) Tom.VI., pp. 327-350.

- (1758) Tom. Vll, pp. 73-92.

Journal encyclopédique par une sociétè de gens de lettres, dédié a Son Alt. Ser. et Emin. Jean Théodore, Duc de Baviére, etc....

A Liege, de l'Imprimerie du Bureau du journal.

- (1759) Tom.I, part. 3, pp. 73-84.

- (1759) Tom.II, part. 1, pp. 82-100.

Journal Étranger ou notíce exacte et détaillée des ouvrages des toutes los nations étrangéres, en fait d'arts, des sciences, de litterature, etc., par M. Fréron, des Académies d'Angers, de Montauban et de Nancy.

A Paris, chez Michel Lambert.

- (1756) Janvier, pp. 3-46.

Journal des savants combiné avec les Mémoires de Trévoux.

A Amsterdam, chez Marc Michel Rey.

- (1758) Sept.-Oct. PP. 353-359.

93 AGI. Caracas, 198. Segunda vía. Respuesta al pliego de veinte y uno de febrero de mil setecientos y quarenta que V. M. se dignó embiar al Prelado de las Missiones de Orinoco de la Compañia de Jhesus, despachado en el Pardo para que informe sobre lo que se huviere obrado en la construccion del Fuerte que V. M. ha mandado hacer en la Angostura del Orinoco. (Gumilla, 1970: 311).

${ }^{94}$ AIUL. Papeletas: Román, Manuel. "Descubrimiento de la comunicación del Orinoco con el Marañón y Relación que hace el P. Manuel Román de su viaje de Carichana al Río Negro: desde el 4 de febrero hasta el 15 de octubre de 1744". 
Su gesta desde la desembocadura del Atabapo hasta el primer establecimiento portugués en el Río Negro, la Misión de los PP. Carmelitas de Mariwá (posteriormente Barcelos), había tenido un recorrido de 1.200 kilómetros de ida y otros tantos de vuelta, toda por los caminos acuáticos del Orinoco, canal de Casiquiare y Río Negro, sin contar el viaje de ida y regreso de Carichana al Atabapo ${ }^{95}$. Y Daniel de Barandiarán anota a continuación que de Mariwá (la última Thule portuguesa de Río Negro) hasta el actual punto fronterizo entre Venezuela y Brasil (la Piedra del Cocuy) "hay más de 600 kilómetros de distancia fluvial ríonegrina succionados por el avance portugués”96.

Varias fueron las consecuencias que se siguieron de este gran viaje exploratorio de Manuel Román. En el ámbito de la geografía jesuítica el Raudal de Atures había dejado de ser el valladar líquido que significaba el "finis terrae" de la realidad conocida hasta entonces como última frontera. Por ello, el descubrimiento del Casiquiare no significa propiamente el comienzo de una etapa de excursiones y viajes misioneros: más bien supone una toma de conciencia ante el enigma real y concreto de la Orinoquia, no sólo en su longitud fluvial, sino con su realidad preocupante de las tierras del interior.

En el ámbito de las ciencias geográficas y cartográficas la asimilación de la nueva realidad de un Orinoco guayanés tardaría mucho tiempo en ser aceptada. Para La Condamine el nuevo descubrimiento significaba la verificación de una tercera anastomosis entre el Amazonas y el Orinoco-Guaviare todavía amazónico: la primera a través del Río Putumayo-Izá, la segunda por el Río Caquetá-Yapurá y la tercera por el Río Negro. La revelación del P. Manuel Román “destruye definitivamente la cosmovisión amazónica del Orinoco" "97 y es el primero en interpretar el origen guayanés de nuestro gran río que huye de sus afluentes gigantes y se esconde detrás de las misiones jesuíticas orinoquenses ${ }^{98}$.

El tercer personaje clave en la elaboración de la nueva frontera sería el P. Bernardo Rotella. Hombre polémico y visionario, al frecuentar la geografía del binomio fluvial Atabapo-Guaviare se convirtió en pieza clave como forjador del nuevo equilibrio interracial en los espacios sur-orinoquenses.

De esta forma consagró sus últimos años misioneros, dentro del esquema de Manuel Román, a la pacificación de la alta Orinoquia y la contención de los esclavistas portugueses $^{99}$. Pero si Gumilla había legado a la posteridad su obra El Orinoco ilustrado y Román el descubrimiento del Casiquiare, Rotella dejaría un valioso "Informe Hidrográfico de Guayana" con un Mapa y donde el Orinoco se retrotrae en su escudo guayanés y nace en el gran Lago de la Parima ${ }^{100}$. Así dejaba el primer testimonio escrito en el que se abandonaban dos siglos y medio de tradición cartográfica que consagraba la realidad ${ }^{101}$ Fig. 3.

Finalmente, lo que no pudieron conseguir ni los gobernadores ni los misioneros lo obtendrían los nuevos aliados indígenas de los jesuitas. En efecto, serían los cabres y

\footnotetext{
${ }^{95}$ Barandiarán, 2000: 474.

${ }^{96}$ Ibíd.: 374.

${ }^{97}$ Ibíd.: 467.

${ }^{98}$ Ibíd.: 475.

${ }^{99}$ Del Rey Fajardo, 2007-2011: 244-257.

${ }^{100}$ Barandiarán, 2000: 474 y ss.

${ }^{101}$ Donís Ríos, 2013.
} 
sobre todos los guaypunabis quienes acabarían de raíz la hegemonía caribe en el Orinoco medio.

El misionero italiano Felipe Salvador Gilij $(1721-1789)^{102}$, que llegó al Orinoco en 1749, debía recordar muy vivamente las historias misioneras como ya superadas, pues escribiría en su Ensayo de Historia Americana (1780) que Puruey "ahora es a modo de quemada Troya humeante memoria de sus triunfos sobre las naciones orinoquenses, si dejando a los valerosos se hubieran contentado con subyugar a los más débiles"103. Y más adelante recordaría que este hecho histórico sería "sobre todo de utilidad para la libertad de las naciones del Orinoco" ${ }^{104}$.

En conclusión: cuando en 1756 hacen acto de presencia las avanzadas de la Expedición en la Misiones jesuíticas ya el P. Manuel Román había descubierto en 1744 la comunicación Orinoco-Amazonas a través del caño Casiquiare; Bernardo Rotella había revelado en 1747 las verdaderas fuentes del gran Orinoco en el macizo guayanés; se habían trajinado los grandes afluentes de la mano derecha del Orinoco como el Suapure, Parguza, Sipapo y Ventuari-Manapiare en el intento de acabar con las incursiones esclavistas caribes; en la región ríonegrina ya en 1751 el P. Roque Lubián intentó llegar a las fuentes del Río Negro en la zona amazónica del Caquetá, Guayavero y Guaviare y cuatro años más tarde completaría esta expedición el P. José Ma . Forneri. Y en las relaciones interétnicas los jesuitas habían logrado la convivencia con los cabres

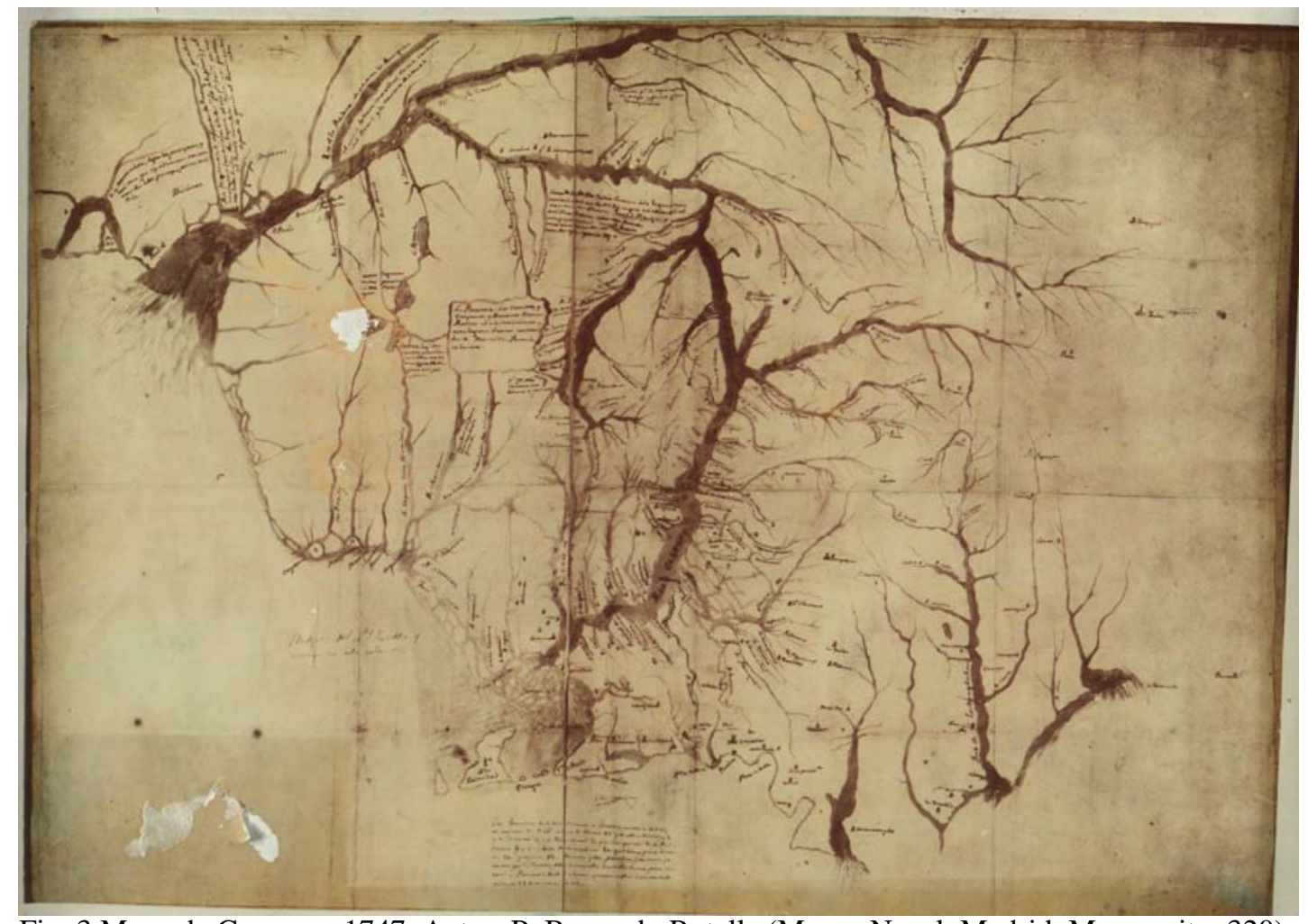

Fig. 3 Mapa de Guayana. 1747. Autor: P. Bernardo Rotella (Museo Naval. Madrid. Manuscrito, 320). Es el primer mapa que verifica que las fuentes del Orinoco no son andinas sino guauanesas.

\footnotetext{
${ }^{102}$ Del Rey Fajardo, 2006: 311-316.

103 Gilij, 1965: 62.

${ }^{104}$ Ibíd.: 57.
}

40 José del Rey Fajardo SJ. El Tratado de Límites de 1750 y el ocaso de la acción ...25-56. 
y guaypunabis ${ }^{105}$.

\section{La presencia de los hombres de la expedición de límites y el ocaso de la acción jesuítica en la Orinoquia.}

A la vista de todos los antecedentes antes señalados trataremos de diseñar algunas claves que ayuden a comprender el ocaso de la acción jesuítica en la Orinoquia tras la llegada de la Expedición de Límites de 1750.

La primera clave para poder entender el declive de la presencia de la orden de Ignacio de Loyola en las grandes geografías amazónicas se sitúa en unos planos que van más allá de las diferencias de objetivos de cada una de las dos corporaciones que, aunque distintas, no debían ser excluyentes.

Para los expedicionarios hispanos era evidente que había que superar la "inercia de siglos" de las misiones e instaurar el "reformismo de frontera". En síntesis, la Guayana, parte vital del olvidado corazón de Sudamérica, debía ser modernizada de acuerdo con las reformas borbónicas.

Así pues, la Expedición de Límites, en principio, era netamente científica y por lo tanto estaba compuesta por marinos, militares, botánicos, cartógrafos, astrónomos, dibujantes, es decir, miembros de una burocracia en ascenso pero desvinculados de los intereses regionales y guayaneses ${ }^{106}$.

Los criterios no podían ser más idealistas: sentar las bases de una nueva racionalidad política, de tipo occidental, con sus reformas políticas, sociales y económicas en las nuevas fronteras tropicales ${ }^{107} \mathrm{y}$ crear nuevos modelos que garantizaran la fidelidad de sus nuevos habitantes al imperio y el control político directo del "espacio" 108 .

Debía imponerse una nueva ideología estatal, laica y regalista capaz de integrar los "espacios vacíos y desiertos” y para ello se requería "el incremento del número de esclavos negros, la mejora de las redes de comunicación y una reforma administrativa que redujera la autonomía de los diferentes poderes locales”109.

Por otra parte, la Compañía de Jesús había luchado desde 1646 por descubrir las inéditas geografías guayanesas, por civilizar al mosaico de naciones autóctonas que integraban la Orinoquia y por ocupar los territorios entre el Orinoco y el Amazonas para la corona española. Pero como telón de fondo siempre se mantuvo el dominio del imperialismo caribe al servicio de la industria azucarera holandesa ${ }^{110}$.

En realidad, se puede afirmar que la relativa paz en la alta Orinoquia comienza a gestarse a partir de 1750. Como hemos analizado en un acápite anterior las guerras

\footnotetext{
${ }^{105}$ Véase: Barandiarán, 1994: 496-497.

${ }^{106}$ Véase: Lucena Giraldo, 1991c. Para la organización de la Expedición, véase: Pelayo y Puig-Samper, 1992: 49-62.

${ }^{107}$ Lucena Giraldo, 1991b.

${ }^{108}$ Sánchez Pérez, 1991: 74.

${ }^{109}$ Lucena Giraldo, 1992-1993: 246.

${ }^{110}$ Del rey Fajardo, 2007.
} 
caríbicas habían desolado las misiones jesuíticas y sólo al mediar el siglo XVIII comenzaron a estructurar su verdadera labor colonizadora a través de la educación y de la construcción de la "aldea ordenada".

Pero estos dos proyectos que debían ser complementarios, pues, aunque disímiles no eran excluyentes, se fueron divorciando de raíz por los Comisarios jefes de la Expedición y a nuestro modo de ver ahí comenzaron los desencuentros entre las dos instituciones.

EL 9 de abril de 1754 llegaban los hombres de la Expedición de Límites a Cumaná. Los poderes omnímodos otorgados al Primer Comisario, José de Iturriaga, venían especificados en las reales cédulas por las que se le confería "la total subordinación de los recursos económicos, militares y de transporte de las gobernaciones que atravesaran a sus necesidades y sus deseos” ${ }^{\text {} 111}$. Su destino final era Mariwá, en el Río Negro para dialogar con la Comisión portuguesa.

Sin embargo, ponto surgieron las hostilidades entre el gobernador de la Nueva Andalucía, Mateo Gual $\left(\dot{c}\right.$ ? -1756) ${ }^{112}$ y don José de Iturriaga, hecho que motivó la destitución del mandatario regional el 27 de diciembre de $1757^{113}$.

En 1755 el grueso de la Expedición llega a Santo Tomé de Guayana, la pobre capital de la gran Provincia del mismo nombre ${ }^{114}$. De nuevo se repite la animosidad del Primer Comisario contra los capuchinos catalanes hasta el punto en que Fray Benito de la Garriga (1711-1783) ${ }^{115}$ considera a los expedicionarios como una verdadera plaga ${ }^{116}$.

El 27 de junio de 1756 abandonaban los territorios capuchinos para dirigirse a Muitaco, capital de las misiones franciscanas en donde con similares acciones vivirían las incertidumbres de los expedicionarios ${ }^{117}$.

Más larga y complicada sería la convivencia de los jesuitas orinoquenses con los miembros de la Expedición de Límites y para su descripción detallada nos remitimos a nuestro libro: Las Misiones germen de la nacionalidad ${ }^{118}$.

Sin embargo, tan previstas se intuían estas antinomias que los organizadores de la Expedición creyeron que la inclusión del jesuita croata, Francisco Javier Haller $(1716-1755)^{119}$ podría neutralizar la convivencia en tierras guayanesas con sus correligionarios. Haller era profesor de la universidad de Gottingen de astronomía y con

\footnotetext{
${ }^{111}$ Lucena Giraldo, 1992-1993: 251.

${ }^{112}$ Fundación Polar, 1997: 582.

113 Ibíd.

${ }^{114}$ García Castro, 1997: 1091-1092.

115 Pérez Vila, 1997: 462-463.

${ }^{116}$ AGS. Estado, 7389. Carta de Fray Benito de la Garriga a Mateo Gual. Suay, 25 de junio de 1756: "Nos acaban de comer las subsistencias, nos destruyen las yucas tiernecitas, se han de rayar para mantenerlos abastimentarlos de cazabe y mañoco (...) todos los días dicen que se van y luego se mira lo contrario, ahora tienen el bastimento propio y no se sabe el secreto que impide su marcha, luego embarcan y más presto vuelven a desembarcar”. Véase: Carrocera, 1979.

${ }^{117}$ Gómez Parente, 1979. En realidad este autor toca tangencialmente el problema de Límites pero es sumamente detallado al analizar las poblaciones franciscanas en el alto Orinoco.

${ }^{118}$ Del Rey Fajardo 2007-2011: 259-292.

${ }^{119}$ Véase: Ibíd.: 255-256.
} 
gran inclinación a los estudios de botánica, cualidad que le hacía abrigar a Pedro Löfling la esperanza de contar con él como un futuro gran colaborador ${ }^{120}$. Pero la muerte le sorprendió en la Isla de Trinidad el 24 de junio de $1755^{121}$.

En síntesis, se puede afirmar que la confianza mutua sufrió múltiples mutilaciones, en última instancia, porque los miembros de la Expedición minusvaloraban a los misioneros como lo demuestra, entre otras razones, el recurrir al “espionaje político" que desarrollaron en torno a todas las órdenes religiosas ${ }^{122}$.

La segunda clave la sintetiza el contexto diplomático hispano-portugués en que se movía la alta política de ambas coronas.

\section{El influjo de Pombal en el ocaso jesuítico en la Orinoquia.}

Es evidente que después de la expulsión de los jesuitas de Portugal y de sus dominios en 1759, la corte española (muy penetrada por el antijesuitismo e influenciada por la campaña del marqués de Pombal (1699-1782) ${ }^{123}$ contra la Compañía de Jesús) tratara de alejar a los jesuitas de sus fronteras con Brasil.

Para la historia orinoquense conviene tener presente que en marzo de 1755 mandaba Pombal a su hermano Francisco de Mendoça Furtado, Gobernador del Marañón, retirar de la frontera hispana a todos los jesuitas portugueses y que interceptase su correspondencia con sus homólogos españoles "pues con este poder eclesiástico nos encontramos actualmente en una situación muy tirante y a dos dedos de la guerra" ${ }^{124}$. Y en marzo del año siguiente daba otro paso al retirar a los jesuitas del Marañón y entregar sus misiones a los PP. Carmelitas ${ }^{125}$.

Todavía más, Pombal asoma en 1758 a la corte española que, en el conflicto jesuítico, la expulsión de los miembros de la Compañía de Jesús de las reducciones guaraníticas podría extenderse a todas las misiones de América ${ }^{126}$. Y en 1759, decretada la expulsión de los jesuitas del Portugal, Gomes Freire proponía al Comisario General español que "si su Católica Majestad tomara una medida semejante, ello significaría un alivio para toda América"127.

\footnotetext{
${ }^{120}$ Riden, 1957: 98-99. Cfr. $1^{\text {a }}$ Carta de Loefling a Linneo. Memorias...1907: 132.

${ }^{121}$ Ramos Pérez, 1946: 174.

${ }^{122}$ Véase: Para los Capuchinos catalanes: Eugenio de Alvarado: "Modo religioso y económico de vivir los padres, granjerías del común de las misiones como del particular de los padres, indios y demás agregados a ellas. 1755” (AGS. Estado, 7390). Sobre el Informe sobre las Misiones jesuíticas hemos hablado más arriba.

123 Leite, 2001: 672-675.

${ }^{124}$ BNL. Seç̧ao Pombalina, 626, fol., 91. Citado por Kratz, 1954: 131.

125 AGS. Estado, 7354. Carta de Aranda a Wall. Lisboa, 21 de marzo de 1756.

${ }^{126}$ Kratz, 1954: 224-225.

${ }^{127}$ AGS. Estado, 7393, fol., 82. Carta de Gomes Freire a Valdelirios. 22 de febrero de 1759, Citado por Kratz, 1954: 237.
} 


\section{Las acciones de don José de Iturriaga}

En el contexto antes explicado es lógico que la forma de retirar de la frontera brasilera a los jesuitas era alejarlos legalmente de unos espacios a los que habían mirado con pasión desde 1645.

El 17 de octubre de 1761 solicitaba don José de Iturriaga a la Corte madrileña que le enviasen 6 clérigos de 40 a 50 años, o capuchinos de la misma edad y de diferentes provincias a fin de que pudieran encargarse de la atención espiritual de Real Corona y de San Carlos de Río Negro. Esta preocupación vino a cristalizar en una Real Orden de 2 de noviembre de 1762 por la que se comisionaba a los capuchinos andaluces de Venezuela "para los nuevos pueblos del Alto Orinoco y Río Negro, señalándoles S. M. por terreno desde el Raudal de Maipures inclusive arriba" ${ }^{128}$.

La situación debió permanecer estacionaria hasta el año 1764 cuando hicieron acto de presencia los capuchinos para tomar posesión de sus nuevas demarcaciones.

El 30 de abril de 1764 partía de Caracas la primera expedición capuchina que debía tomar posesión de las nuevas demarcaciones ${ }^{129}$. Estaba integrada la misión por los PP. Jerónimo de Gibraltar (1723-1792) ${ }^{130}$, José Antonio Jerez de los Caballeros y Gregorio de Benacoaz ${ }^{131}$. En su recorrido el lugar de hospedaje fue el de las misiones jesuíticas hasta su llegada al Raudal de Maipures ${ }^{132}$, reducción a cargo del jesuita P. Francisco del Olmo ${ }^{133}$.

Diera la impresión de que los capuchinos no lograron la posesión de San José de Maipures en su primer viaje en 1764 y se hace alusión a una carta del Superior jesuita de fecha 27 de septiembre de 1764.

\footnotetext{
${ }^{128}$ AGI. Caracas, 205. Carta del P. Fernando Ardales al Rey. Misión de Caracas, 30 de mayo de 1764. El P. Ardales había recibido dos comunicaciones sobre este asunto: la primera fechada el 12 de noviembre de 1762 y la segunda el 28 de febrero de 1763.

${ }^{129}$ Aunque Carrocera, 1972: 187, nota, 6, cita el testimonio del P. Ardales (AGI. Caracas, 205. Carta del P. Fernando de Ardales al Rey. Misión de Caracas, 30 de mayo de 1764) sin embargo, creemos que la fecha dada está equivocada ya que por el contexto de los hechos pereciera que debía ser el año 1764 y no el 1763 como pone Ardales. En efecto, en AGI. Caracas, 12 hay una carta del Prefecto, Fernando de Ardales, fechada el 15 de enero de 1765 en la que pone la partida de Caracas el 30 de abril de 1764. Así lo confirma una Carta de don José Solano al Excmo. Señor Baylio Frey Don Julián de Arriaga. Caracas, 24 de abril de 1764 (AGI. Caracas, 440): "... facilité las dificultades que me propuso [el Prefecto de las Misiones Capuchinas] y le detenían; y acordó con el Superior de las Misiones Jesuitas de Orinoco, quien casualmente se halla en esta ciudad, que un religioso de esta comunidad (...) debe hacer la entrega a dos religiosos capuchinos, que a la ligera saldrán de aquí mañana, en conformidad de lo que el Rey ordena; los demás religiosos seguirán luego que empiece el Río Orinoco sus bajantes".

${ }^{130}$ Armedalla, 1997: 496.

${ }^{131}$ AGI. Caracas, 205. Carta del P. Fernando Ardales al Rey. Misión de Caracas, 30 de mayo de 1764.

${ }^{132}$ Del Rey Fajardo, 2011: 265.

133 "Representación del Procurador de los Jesuitas" [Padre Jaime de Torres]. En: Cuervo, 1893: 282-284. Lamentablemente el documento no está datado pero está escrito en los primeros meses de 1765 ya que hace referencia a una carta del Superior del Colegio de Caracas fechada el 12 de diciembre de 1764. Establecemos el año 1764 como fecha de la Representación del Procurador de los Jesuitas porque narra el regreso de los tres misioneros capuchinos de la Misión del Alto Orinoco como reciente y por una carta del Superior de las Misiones jesuíticas, P. Felipe Salvador Gilij, el 27 de agosto los mencionados capuchinos se encontraban de regreso cerca de la Urbana (ANB. Miscelánea, t. 31, fol., 762).
} 
Sin embargo, un mes antes, el 27 de agosto, escribía el P. Felipe Salvador Gilij, Superior de las misiones, a su homólogo capuchino:

"Me causa no poca admiración la noticia que tengo de la no esperada vuelta de Vuestras Paternidades y asi como me condoliera con Vuestras Paternidades a proceder de alguna enfermedad que les haya sobrevenido, asi me fuera de extremo sentimiento si hubiese procedido de la más mínima oposición de parte del P. del Olmo pues a dicho Padre tengo ordenado les hiciera entrega del Pueblo del Raudal de Maypures sin admitir ninguna interpretación que dicho Padre, como Cura, pudiese hacer de esta mi orden. Tenía determinado subir a encontrarme con Vuestras Paternidades pero receloso de errarlo en el camino, comunico mis veces al P. Procurador Francisco Riberos, quien según lo que tengo hablado con su $R$. hará a Vuestras Paternidades la entrega de dicho Pueblo. Quedo a la obediencia de V. P. rogando a Dios me les /ilegible/ como deseo. Urbana y agosto 27 de 1764 "134.

El asunto parece ser más complejo sobre todo si se lee con detención la contestación del capuchino que a todas luces venía de regreso para la capital venezolana.

Dos días después, el 29 de agosto, contestaba Fray Gerónimo de Gibraltar la carta del Superior P. Gilij en los siguientes términos:

“Digo yo Fr. Gerónimo de Gibraltar Religioso Capuchino y Presidente de las Misiones del Alto Orinoco que comienzan desde el Raudal de Cuituna inclusive; que en vista de la carta de la bta. del R. P. Ph. Gilij de la Compañía de Jesús Superior de las Misiones de Orinoco que me entregó el día de la fecha el P. Francisco Riberos de la misma Compañía y Procurador de dichas Misiones, doyme por entregado con toda la formalidad necesaria de dicho Raudal de Cuituna en lo que mira al pie en que de presente se halla de vecinos blancos $e$ indios mediante la citada carta del R. P. Superior Ph. Gilij y presento donde conventa. Doy la presente certificación a pedimento del nombrado Padre Francisco Riberos. En el sitio de Gual/ilegible/ frente al cerro llamado El Castillo a 29 de agosto de 1764"135.

En enero de 1765 se ponía en marcha la segunda expedición capuchina a las demarcaciones alto orinoquenses a ellos asignadas. Iba por Superior el P. José Antonio Jerez de los Caballeros y completaba la expedición: Domingo José de Campillos, Andrés de Antequera, José Luis de Sevilla, Felipe de Málaga y Alonso de Castro ${ }^{136}$. Habían llegado a Cabruta el 6 de enero de $1765^{137}$ pero sólo pudieron emprender su viaje el 28 de enero de $1765^{138}$. Llegaron a San José de Maypures el 22 de febrero ${ }^{139}$.

\footnotetext{
${ }^{134}$ ANB. Miscelánea, t. 31, fol., 762.

${ }^{135}$ Ibíd.: fol. 762v.

${ }^{136}$ No conocemos reseñas biográficas de estos capuchinos. Sin embargo sus acciones pueden seguirse en: Carrocera, 1979.

137 AGI. Caracas, 440. Exorto del R. P. Fray Joseph Antonio Xerez pidiendo escolta de tropa, embarcaciones y órdenes al fin de su introduzion y la de su comunidad ala alto Orinoco y Rio Negro. Ciudad Real del Orinoco, 12 de enero de 1765.

${ }^{138}$ Ibíd. Carta de Fray José Antonio Jerez de los Caballeros a don José de Iturriaga. Cabruta y enero 27 de 1765: "Mañana salimos, si Dios quiere...". Carta de don José Solano a don Julián de Arriaga. Caracas, 5 de mayo de 1765 (Lodares, 1929: 312).
} 
El 28 de febrero iniciaron los capuchinos el recorrido del área misional a ellos asignada, no sin antes haber dejado al frente de la reducción de San José de Maypures al P. Andrés de Antequera ${ }^{140}$. La expedición hasta Río Negro duraría 32 días pues el $1^{\circ}$ de abril por la tarde arribaban a San Carlos con la profunda desolación de verificar que las poblaciones que había dejado la Comisión de Límites se habían reducido a un recuerdo ${ }^{141}$.

Después de haber fundado los capuchinos a San Carlos y San Francisco Solano, dejó el P. Jerez de los Caballeros como párroco al P. Felipe de Málaga e inició el viaje de retorno a Caracas en donde ya se encontraba en febrero de $1766^{142}$.

En un tercer viaje, el P. Jerez de los Caballeros abandona Caracas el 20 de abril de 1766 y se dirige a Guayana en donde permanecería hasta el 2 de febrero de 1767. Una vez provisto allí por el gobernador Manuel Centurión (1732-1800) ${ }^{143}$ de todo lo necesario, remontó 400 leguas hasta llegar a la Esmeralda. Pero, en el lugar de los hechos pudo verificar que solamente le quedaban los PP. Antequera y Málaga y por ello decidió regresar una vez más a la capital caraqueña a fin de solicitar nuevos refuerzos $^{144}$. Mas, para estas fechas ya se había consumado la expulsión de los jesuitas del Orinoco y por ende es historia que se desvía de nuestro propósito.

Paralelamente, los jesuitas, una vez que se desencadenó la serie de disposiciones legales que asignaban a los capuchinos las misiones del alto Orinoco y tras poner en práctica las disposiciones civiles-administrativas, comenzaron a actuar de acuerdo a los procedimientos de ley.

En mayo de $1765^{145}$ podía el P. Jaime de Torres (1711- ¿? $)^{146}$, Procurador de la Provincia del Nuevo Reino de Granada en Madrid, elevar ante el Consejo de Indias una Representación que venía avalada con una carta del Superior de las Misiones del

${ }^{139}$ Informe de 8 de febrero de 1766 del Presidente de las nuevas poblaciones del Alto Orinoco y de Río Negro al Capitán General de Venezuela (Lodares, 1929: 317). Por carta del P. Provincial de Andalucía al P. José Antonio Jerez de los Caballeros fechada en Cádiz el 15 de octubre de 1765 accede a que lleven los misioneros vida de comunidad (BNM. Mss. 3649, fol. 290).

${ }^{140}$ Carrocera, 1972: 188.

${ }^{141}$ AGI. Caracas, 440. Informe de 8 de febrero de 1766 del Presidente de las nuevas poblaciones del alto Orinoco y Río Negro a la Capitanía General de Venezuela. José A. Jerez de los Caballeros. [El documento lo trascribe Lodares, 1929: 317-319]. En este escrito nos dejará constancia de San Fernando "ya destruída"; del Raudal de Santa Bárbara "en cuya situación encontré aun los resquicios de la fundación que V. S. allí emprendió con el capitán Imo y sus gentes"; de la Garita de la Buena Guardia, a la entrada del Casiquiare "en cuyo distrito no hallamos más población de indios que la del Capitán Daviaje".

${ }^{142}$ En Caracas data el P. Jerez su informe de 1766 el día 8 de febrero (Lodares, 1929: 319).

143 Avendaño Vera, 1997: 774-776.

144 José. A. Jerez de los Caballeros: "Informe del 17 de marzo de 1768 del Presidente de las nuevas poblaciones del alto Orinoco y de Río Negro al Capitán General de Venezuela". En: Lodares, 1929: 319323.

145 AGI. Caracas, 440. Madrid. El Padre Jayme de Torres de la Compañia de Jesus Porocurador de las Provinczias de tierra firme. [S/f]. Sin embargo, en el mismo expediente existe otra carta del P. Torres en la que afirma: "... dice, que en el mes de Mayo de el año pasado de 1765 presentó a V. M. un Memorial..." (El Padre Jayme de Torres de la Compañia de Jesus Procurador de las Provincias de Nuevo Reyno y Quito... [S/f]). El texto lo reproduce Cuervo, 1893: 282-284.

${ }^{146}$ Del Rey Fajardo, 2006: 700-703. 
Orinoco en la que comunicaba la forma cómo se hizo la entrega del pueblo del Raudal de Maypures y con otra misiva del Superior del Colegio de Caracas fechada el 12 de diciembre de $1765^{147}$.

Dos razones fundamentales argumenta el P. Torres en favor de la Compañía de Jesús. La primera, la Real Cédula del 16 de septiembre de 1736 cuyo espíritu "a más del superior servicio de ambas Magestades, fue conservar la paz, unión y concordia entre dichas religiones". La Real Cédula aducida se refiere a la aprobación de la Concordia de Guayana (20 de marzo de 1734) por la que se dividió el territorio guayanés entre los franciscanos de Píritu, los capuchinos de Guayana y los jesuitas del Orinoco ${ }^{148}$. La segunda, que "jamás se ha pedido a la Compañía Misionero" para las poblaciones que están en Río Negro.

Es muy ilustrativa la nota que le adjunta a la carta citada del P. Jaime de Torres el Consejo de Indias:

La cedula que cita fue expedida por el Consejo.

"En orden de 29 de Julio de 1763 se previno a Solano cuidase de las Misiones del Alto Orinoco; en 24 de abril de 1764 avisó haber dispuesto enviar seis Religiosos Capuchinos y acordado con el superior de las Misiones de la Compañía que les entregasen los pueblos de San Fernando y Maypures de que interinamente cuidaba un Jesuita; en orden de 24 de septiembre siguiente se le advirtió que en punto a destinar Capuchinos a los Pueblos citados camine con el resguardo de si según Reales concesiones pertenece a este Religión u otra aquel distrito por no perjudicar a quien tenga el Derecho si se exhibiese a lo mismo.

No ocurra otra providencia que enviarle este recurso repitiéndole la anterior orden. Fecho en 21 de Mayo de 1765"149.

Así pues, antes del informe presentado en mayo de 1765 por el P. Jaime de Torres, obedece la siguiente nota consultiva remitida por el Baylío don Julián de Arriaga el 21 de mayo de 1765 a don José Solano:

“Copia. No obstante estar prevenido a V. S. en orden de 24 de septiembre antecedente que en punto a destinar Capuchinos a los Pueblos del Alto Orinoco caminase con el resguardo de si según reales concesiones pertenece para no perjudicar a quien tenga el derecho si se exiviese a lo mismo; me manda el Rey advertir a V. S. nuevamente, en vista de la adjunta representación del Procurador de la Compañía de las Provincias de Tierra Firme, que enterándose V. S. de la Concordia que cita y Cédula expedida en su virtud, coopere a que con la mejor armonía cuiden los respectivos superiores de que los Pueblos de las jurisdicciones que les correspondan estén bien asistidos de Misioneros ${ }^{150}$.

\footnotetext{
${ }^{147}$ AGI. Caracas, 440. Madrid. El Padre Jayme de Torres de la Compañia de Jesus Porocurador de las Provinczias de tierra firme. (Cuervo, 1893: 282-284).

${ }^{148}$ El texto puede verse en: Gumilla, 1970: 101-105.

149 AGI. Caracas, 440. Madrid. El Padre Jayme de Torres de la Compañia de Jesus Procurador de las Provinczias de tierra firme.

150 AHN. Jesuitas, 249, fol., 191. El original se encuentra en AGI. Caracas, 440. Año de 1766. Expediente relativo a las Misiones Capuchinas del Alto Orinoco y Rio Negro.
} 
No parece haber reparado mucho el Gobernador de Caracas a los planteamientos formulados por la Corte hispana. Existe una carta de Solano a Arriaga, fechada en Caracas el 5 de mayo de 1765, que, responde al requerimiento del Consejo de Indias del 24 de septiembre de 1764:

"Esto es, Excmo. Señor, lo que me consta y que las Misiones CapuchinoCatalana, Observante franciscana y Jesuita, tienen cada una un territorio inmenso en qué ejercitar y aprovechar su fervoroso celo por el bien de las almas y que la Misión Capuchina de la Provincia de Andalucía que ha poblado y reducido al gremio de la Iglesia los indios de esta Provincia de Venezuela, no tiene ya en qué emplearse, y puede, como ha determinado la piedad del Rey, pasar a trabajar desde luego en el bien de aquellas almas, sin que otros padezcan por su falta; no obstante, si averiguare que a otra comunidad pertenecía aquel territorio por concesión anterior, daré parte a V. E.” "

Del análisis del texto transcrito de Solano se desprenden varias conclusiones. El tema sometido a consulta es soslayado de plano por el Gobernador de Caracas al no hacer referencia alguna sobre la Concordia de Guayana (20 de marzo de 1734) que mereció la aprobación real el 16 de septiembre de $1736^{152}$. El documento aducido asignaba a los jesuitas desde el río Cuchivero "lo restante del Orinoco, tirando siempre para arriba, y yendo siempre unos y otros linderos o demarcaciones línea recta de Orinoco al Marañón y Amazonas" ${ }^{153}$. En consecuencia, al asignar a los capuchinos andaluces el alto Orinoco se conseguía un doble efecto: despojar a los jesuitas de su supuesto dominio y predominio de la geografía orinoquense y emplear a los capuchinos en una región bien difícil porque al parecer no tenían en la Provincia de Venezuela "gentiles en qué emplearse".

Finalmente, no conocemos ningún escrito a los superiores jesuíticos en los que se les solicitase personal para esas misiones, así en la correspondencia de Iturriaga se hable siempre de que no tiene la Compañía de Jesús sujetos para la empresa del alto Orinoco.

Las tácticas dilatorias de Solano hicieron que el problema legal se postergara de tal forma que sólo se planteara en Caracas en 1766 cuando ya los hechos cumplidos habían interpuesto tiempo y espacio para hacer prácticamente inválida cualquier reclamación.

En efecto, el 14 de junio de 1766 solicitaba Fray José Antonio Jerez de los Caballeros de don José de Iturriaga la certificación de una serie de puntos para ser tenidos en cuenta en la demanda que los Jesuitas llevaban en Madrid por la adjudicación de las misiones del alto Orinoco a los Capuchinos. El 18 de junio contestaba el Comandante General del Orinoco y Río Negro:

\footnotetext{
${ }^{151}$ Carta de don José Solano a don Julián de Arriaga. Caracas, 5 de mayo de 1765 (Pereira, 1883: 126). (El subrayado es nuestro).

152 AGI. Santo Domingo, 590. S. M. aprueba y manda se observe la Concordia celebrada por los religiosos Misioneros de la orden de san Francisco; de la Compañía de Jesús y Capuchinos, sobre los territorios en que han de ejercer su sagrado instituto en la provincia de Cumaná. San Ildefonso, 16 de septiembre de 1736. Es conveniente anotar que el documento se añade: "Se imprimieron 13 y entregaron a Fray Francisco del Castillo".

${ }^{153}$ Gumilla, 1979: 103.
}

48 José del Rey Fajardo SJ. El Tratado de Límites de 1750 y el ocaso de la acción ...25-56. 
“Habiendo condescendido S. M. como consta a V. P. R. di paso a la entrada en el alto Orinoco de los primeros tres Reverendos Padres Capuchinos y llegados a Maypures no lograron allí la posesión de aquel Pueblo, pero de retirada firmó el Reverendo Padre Presidente, entonces, la entrega de él al Reverendo Padre Superior de las Misiones Phelipe Gili según éste me avisó en carta de viente y siete de septiembre de 1764. Diciendo también que el Padre Francisco del Olmo debía haber hecho la entrega de dicho Pueblo, permitiéndole solamente el recurso al Arzobispo de Santa Fe y que VV. PP. habían convenido con el referido Padre Olmo que en conciencia no debía hacer dicha entrega sin los despachos del dicho Señor Arzobispo.

Aun dado el recibo de la posesión no podían Vuestras Paternidades volver a Maipures por las enfermedades que les sobrevinieron en este viaje que es una de las causas del retroceso desde aquel Pueblo, en cuya fundación no tuvieron parte los Padres de la Compañía por reducción de indios, fábrica de casa, ni iglesia, ni el Reverendo Padre Olmo dejó en él, con noticia mía, cosa que fuese suya. Tampoco volvió allá a administrar algunos sacramentos, ni decir misa durante la ausencia de V. Paternidad Reverenda"154.

Con la documentación de que disponemos podemos reconstruir la verdad, sutilmente tergiversada, por don José de Iturriaga. Más arriba hemos transcrito las actas de los dos Superiores -jesuita y capuchino- en agosto de 1764.

Todavía más, en su carta del 26 de junio de 1766, el mismo Iturriaga censura que el P. del Olmo "tampoco volvió allá [Maypures] a administrar algunos sacramentos, ni decir misa durante la ausencia de Vuestra Paternidad Reverenda porque en una ocasión que hizo el viaje no se verificó alguna de estas diligencias" ${ }^{155}$. Según lo escrito por Iturriaga, cabe preguntarse: entregó el P. del Olmo el pueblo de Maipures o no; si lo primero, por qué le van a recriminar que no regresó; si lo segundo, cómo se explica la aceptación de Fray Jerónimo de Gibraltar y el abandono de una parroquia por la que luchaba en permanecer!.

Pero a título ilustrativo para conocer lo tendencioso de la información de Iturriaga, transcribimos lo que el 5 de mayo de 1765, -un año antes de la carta que hemos citado de Iturriaga- escribía el Gobernador de Caracas, don José Solano:

"A este tiempo recibo la de $V$. E. en que se sirve prevenirme que por lo que respecta a estos religiosos que pasaron a encargarse de las Misiones, que interinamente tenían los Jesuitas, de los Pueblos de San Fernando y Maypures (...) debo hacer presente a V. E. que habiendo pacificado yo la Nación Guypunavi y otras del alto Orinoco, estableciendo mi cuartel, a principios del año de cincuenta y ocho, en el sitio que nombré/ San Fernando, distante once días de navegación río arriba, intermedio el Raudal de Maypures del Pueblo de San Juan Nepomuceno del Raudal de Atures, último y fontera de la Mision Jesuita de Orinoco, Don Joseph de Yturriaga me envió familias de la Provincia de Caracas y de la Margarita para fundar allí un Pueblo / de Españoles, y el

\footnotetext{
154 AGI. Caracas, 206. Expediente sobre haberse intentado por los Padres Jesuitas despojar a los religiosos Capuchinos de la Provincia de Andalucía de las Misiones que están a su cargo en el Río Negro y Alto Orinoco (1767). (Del Rey Fajardo, 1974: 409).

155 AGI. Caracas, 206. Carta de José de Iturriaga a Fray José Antonio de Jerez. Ciudad Real del Orinoco, 18 de junio de 1766 (Del Rey Fajardo, 1974: 409).
} 
año de sesenta pidió en Santa Fee don Eugenio Albarado un Cura para dicho Pueblo, y bajó con la colación del el Padre Francisco del Olmo, religioso jesuita, como en efecto le dejé ejerciendo su Ministerio cuando por orden de S. $M$. me retiré a estos Reynos: al tiempo que subieron los tres primeros / religiosos Capuchinos a hacerse cargo de la Doctrina de los Yndios del alto Orinoco y Río Negro como S. M. manda, se hallaría aquel religioso Jesuita en el Pueblo de Yndios de San Joseph de Maypures; y como la cédula expresamente se les encarga aquel Pueblo como primero inclusive de los que $S$. M. les concede, y el de / San Fernando ya estaba destruido, por cuya causa el religioso se había bajado a aquel de Maypures con algunos pocos españoles, resto del de San Fernando, se retiró a sus Misiones. Esto es Ecmo. Señor lo que me consta ..." 156 .

Pero don José de Iturriaga seguía en su campaña contra los jesuitas. El 20 de febrero de 1765 le escribía al Baylío Frey Pedro Mesía de la Cerda (1700-1783) indicándole las dificultades que experimentaba la expedición capuchina para subir al alto Orinoco por falta de escolta y de competentes embarcaciones, y añade

“... respondí no ser de mi cargo lo que pretendía, pero como reflexioné la pérdida de tiempo que se seguiría en deservicio de ambas Magestades y el poder desfallecer los ánimos Religiosos del fin santo de su destino, como antes se experimentó con el motivo de no haberles querido entregar el Pueblo de Maypures el Padre Francisco del Olmo, los habilité con dos únicas embarcaciones que se carenaron ${ }^{157}$.

No contento el Comandante del Orinoco con falsear la verdad del P. Francisco del Olmo, aprovecha la oportunidad para insinuarle al Virrey santafereño "la renuencia y displicencia de los ánimos de aquellos Religiosos en cumplir mis disposiciones en mejor servicio de Dios y del Rey"158.

Ante esta actitud hostil y descalificadora de Iturriaga frente a los jesuitas, era lógico que se diera -como contrapartida- en el ánimo de los misioneros animadversión y recelo ante lo que se podrían calificar como caprichos del ya viejo y cansado marino vasco. Con todo, por parte de los miembros de la Compañía de Jesús hubo siempre respeto y acatamiento como lo demuestra la contestación que da Gilij a una carta del Comandante General del Orinoco:

“Muy Señor mío. Recibo la de V. S. de 10 del pasado y dándome V. S. en ella varias quejas, digo: a la primera, que no me parece reprensible el Padre Olmo por el exorto hecho al Alferez Santos a que entregase a los soldados consabidos sus mujeres; así lo lleva le ley evangélica del matrimonio; así parecía la voluntad presunta de V. S. quien ordenando a los soldados salir de Maypures para estos pueblos, parecía consecuencia legítima que fuese con sus mujeres y más pidiéndolo ellas mismas, y valiéndose para esto, como se valieron, de la autoridad de un sacerdote y siendo en ello tan empeñados sus maridos que como V. S. me dice, volvieron por ellas de noche al tercer día. Si en esto hay

\footnotetext{
${ }^{156}$ AGI. Caracas, 440. Carta de don José Solano a don Julián de Arriaga. Caracas, 5 de mayo de 1765. (Lo subrayado es nuestro).

157 AGI. Caracas, 440. Carta de don José de Iturriaga al Baylío Frey don Pedro Mesía de la Zerda. Ciudad Real del Orinoco, 20 de febrero de 1765. (El subrayado es nuestro).

158 Ibíd.
}

50 José del Rey Fajardo SJ. El Tratado de Límites de 1750 y el ocaso de la acción ...25-56. 
algún yerro será de los soldados. A la segunda reconvine al P. Olmo, quien dice tener testigo abonado, de que la bajada de Capana fue sin noticia suya. No puedo saber si el Misionero que fue antes del Raudal de Atures y que pasó a las misiones de Meta, pretendió a dicho indio. Si es así, no es de extrañar porque pertenecía a su pueblo y era prestado, según entiendo, hasta establecer en el Raudal de Maypures el pueblo que hay. A la tercera no puedo ser responsable pues no lo han hecho de orden mía. A la cuarta y quinta no es concebible que por uno o dos indios se valiesen los Padres del pretexto de enfermedad para detenerlos en sus pueblos. Yo ciertamente no me valí de tan leve pretexto, y menos de la interposición del nombre de Dios y del Rey (nombres venerables y para usarlos en cosas de importancia) para permitir quedasen en este Pueblo dos indios Areverianas. Se huyeron del Raudal de Maypures y volvieron por industria del Padre Olmo, quien para que no repitiesen la fuga envió a este Pueblo.

Estos, y los demás que nombra $V$. S. están al servicio del Rey Nuestro Señor; y yo, conformándome a lo dispuesto por el Señor Virrey en carta al padre Olmo, soy de parecer que $V$. S. les haga preguntar si quieren ir a dicho Raudal y si quieren ir, que vayan en buena hora; pues, ocho almas, que pueden ser por todos, no son bastantes para remediar los atrasos de estas Misiones; y si no quieren, que no vayan. Yo no me he apartado en nada de lo dispuesto por su Excelencia y me glorío de servir al Rey mejor que ninguno.

Dios guarde a V. S. muchos años. Encaramada y febrero 9 de 1765 ”.

Con todo, la política de la corte de Madrid consistía en retirar a los jesuitas de las fronteras colindantes con las brasileñas ya que los siete pueblos de misiones del Paraguay se habían convertido en un verdadero problema internacional.

En el caso específico de las misiones orinoquenses no cabe la menor duda de que fueron Iturriaga y Solano los que encendieron el conflicto territorial sobre el alto Orinoco, con lo cual enfrentaron a dos familias religiosas (capuchinos y jesuitas) y distrajeron tiempo y hombres en una lucha que bien se puede considerar estéril.

En resumen, la llegada de la Expedición de Límites de 1750 a tierras venezolanas significó el ocaso de la acción jesuítica en esas ingentes y despobladas geografías y frustró el gran "proyecto del sur” de los seguidores de Ignacio de Loyolas por hipotecar una realidad histórica a los intereses políticos que rigieron la diplomacia española en la segunda mitad del siglo XVIII.

\section{Referencias}

Archivos

AGI, Archivo General de Indias, Sevilla.

AGS, Archivo General de Simancas.

AHN, Archivo Histórico Nacional. Madrid.

\footnotetext{
${ }^{159}$ AGI. Caracas, 440. Carta del P. Felipe Salvador Gilij a don José de Iturriaga. Encaramada, febrero 9 de 1765.
}

51 José del Rey Fajardo SJ. El Tratado de Límites de 1750 y el ocaso de la acción ...25-56. 
AIUL, Archivo inédito Uriarte-Lecina. Madrid.

ANB, Archivo Nacional de Colombia, Bogotá.

BPM, Biblioteca de Palacio. Madrid.

BNL, Biblioteca Nacional de Lisboa.

BNM, Biblioteca Nacional de Madrid.

MNM, Museo Naval de Madrid.

\section{Bibliografía}

Alcaraz Gómez (1995), Jesuitas y reformismo. El Padre Francisco de Rábago (17471755). Valencia: Facultad de Teología San Vicente Ferrer. Series Valentina.

Année Littéraire (1758) par M. Fréron, des Académie d'Angers, Montauban, de Nancy, de Marseille et de Caen. A Amsterdam. Et se trouve a Paris chez Michel Lambert.

Armellada, Cesáreo de. (1997), “Gibraltar, Jerónimo de”. En: Fundación Polar Diccionario de Historia de Venezuela. Caracas, Fundación Polar, T. II.

Astraín, Antonio (1925), Historia de la Compañía de Jesús en la Asistencia de España. Madrid: Razón y Fe, T. VII.

Avendaño Vera, Astrid (1997), “Centurión Guerrero, Manuel”. En: Fundación Polar. Diccionario de Historia de Venezuela. Caracas, Fundación Polar, T. I.

Barandiarán, Daniel de (1992), “El Orinoco amazónico de las Misiones jesuíticas”. En: Del Rey Fajardo SJ, José (1992), Misiones jesuíticas en la Orinoquia, San Cristóbal: Universidad Católica del Táchira, T. II.

(1994), "Brasil nació en Tordesillas. (Historia de los límites entre Venezuela y Brasil). Primera Parte: 1494-1801”. En: Paramillo. San Cristóbal, 13.

(2000), “La crónica del Hermano Vega 1730-1750”. En: Vega, Agustín de, Noticia del principio y progresos del establecimiento de las Missiones de gentiles en la río Orinoco por la Compañía de Jesús. Estudio introductorio: José del Rey Fajardo sj y Daniel de Barandiarán. Caracas, Academia Nacional de la Historia.

Boxer, Charles (1953), "Comercio e contrabando entre Bahía e Potosí no século XVI". En: Revista de Historia. Sao Paulo, IV.

Calvo, Carlos (1862), Colección completa de los tratados, convenciones, capitulaciones, armisticios y otros actos diplomáticos de todos los estados de la América Latina: comprendidos entre el golfo de Méjico y el cabo de Hornos desde el año de 1493 hasta nuestros días ... Paris: A. Durand, II.

Caraman, Philip y Baptista, Javier (2001), “XI. Tratado de Límites, 1750”. En: O’Neill, Charles E. y Domínguez, Joaquín $\mathrm{M}^{\mathrm{a}}$. Diccionario histórico de la Compañía de Jesús. Roma-Madrid, T. I. 
Carrocera, Buenaventura de (1972), Misiones de los Capuchinos en los Llanos de Caracas, Caracas: Academia Nacional de la Historia, I.

Cassani, Joseph (1741), Historia de la Provincia de la Compañía de Jesús del Nuevo Reino de Granada, en la América, Madrid: Manuel Fernández, impresor de libros.

(1967), Historia de la Compañía de Jesús del Nuevo Reyno de Granada, Caracas: Academia Nacional de la Historia.

Cuervo, Antonio B. (1893), Colección de documentos inéditos sobre la Geografía y la Historia de Colombia, Bogotá: Imprenta Zalamea hermanos, III.

De La Camoa, Hermenegildo (2001), “Hervás y Panduro, Lorenzo”. En: O’Neill, Charles E. y Domínguez, Joaquín $\mathrm{M}^{\mathrm{a}}$. Diccionario histórico de la Compañía de Jesús. Roma-Madrid, T. II.

Del Rey Fajardo SJ, José (1966), Documentos jesuíticos relativos a la Historia de la Compañía de Jesús en Venezuela, Caracas: Academia Nacional de la Historia.

(1974), Documentos jesuíticos relativos a la Historia de la Compañía de Jesús en Venezuela, Caracas: Academia Nacional de la Historia, T. II.

(1996), “Topohistoria misional jesuítica llanera y orinoquense”. En: Del Rey Fajardo SJ, José y Samudio, Edda O., Hombre, Tierra y Sociedad, San Cristóbal-Bogotá.

(2006), Biblioteca de escritores jesuitas neogranadinos, Bogotá: Editorial Pontificia Universidad Javeriana.

(2007-2011), Los jesuitas en Venezuela. Tomo II-III- IV-V: CaracasBogotá: Universidad Católica Andrés Bello-Pontificia Universidad Javeriana.

Donís Ríos, Manuel Alberto (2013), La Provincia de Guayana para mediados del siglo XVIII. Una visión a través del Mapa del P. Bernardo Rotella S. J. Caracas: Academia Nacional de la Historia.

Elorduy, Eleuterio (2001), “Suárez, Francisco”. En: O’Neill, Charles E. y Domínguez, Joaquín $\mathrm{M}^{\mathrm{a}}$. Diccionario histórico de la Compañía de Jesús. Roma-Madrid, T. IV.

Elliot, John H. (2006), Imperios del mundo atlántico. España y Gran Bretaña en América. Madrid: Taurus.

Fundación Polar (1997), “Gual y Pueyo, Mateo”. En: Diccionario de Historia de Venezuela. Caracas, Fundación Polar, II.

García Castro, Álvaro (1997a), “Guayana provincia de”. En: Fundación Polar, Diccionario de Historia de Venezuela. Caracas; Fundación Polar, II.

(1997b). "Santo Tomé de Guayana”. En: Fundación Polar, Diccionario de Historia de Venezuela. Caracas, Fundación Polar, III.

Gilij, Felipe Salvador (1965); Ensayo de Historia Americana, Caracas: Academia Nacional de la Historia, 3 vols. 
Gómez González, Sebastián (2014), Frontera selvática. Españoles, portugueses y su disputa por el noroccidente amazónico, siglo XVIII. Bogotá: Instituto Colombiano de Geografía e Historia.

Gómez Parente, Odilo (1979), Labor Franciscana en Venezuela: I. Promoción indígena, Caracas: Universidad Católica Andrés Bello.

Gumilla, José (1970), Escritos varios. Estudio preliminar y compilación del P. José del Rey S. J. Caracas: Academia Nacional de la Historia. la Historia.

Hervás y Panduro, Lorenzo (2007), Biblioteca jesuítico-española (1759-1799). Estudio introductorio, edición crítica y notas: Antonio Astorgano Abajo. Madrid: Libris, Asociación Libreros de viejo.

Hochwälder, Fritz (1941), Das heilige Experiment, Zurich

Journal des savants combiné avec les Mémoires de Trévoux (1758) A Amsterdam, chez Marc Michel Rey.

Journal encyclopédique par une sociétè de gens de lettres, dédié a Son Alt. Ser. et Emin. Jean Théodore, Duc de Baviére, etc.... (1759), A Liège : de l'Imprimerie du Bureau du journal.

Journal Étranger ou notíce exacte et détaillée des ouvrages des toutes los nations étrangéres, en fait d'arts, des sciences, de litterature, etc., (1756) par M. Fréron, des Académies d'Angers, de Montauban et de Nancy. A Paris, chez Michel Lambert.

Julián, Antonio (1951), La perla de América provincia de Santa Marta, Bogotá: Ministerio de Educación Nacional.

Kratz, Guillermo (1954), El tratado hispano-portugués de límites de 1750 y sus consecuencias, Roma: Institutum Historicum S. I.

Lacoure, Jean (1993), Jesuitas. I. Los conquistadores, Barcelona-Buenos Aires-México: Ediciones Paidós.

Leite, António (2001), “Carvalho, Sebastiao José de. Pombal (marqués de). En: O’Neill, Charles E. y Domínguez, Joaquín $\mathrm{M}^{\mathrm{a}}$. Diccionario histórico de la Compañía de Jesús. Roma-Madrid, T. I.

Lodares, Baltasar de (1929), Los franciscanos capuchinos en Venezuela. Documentos referentes a las Misiones Franciscanas en esta República. Caracas, Cía. Anon. Edit. Empresa Gutenberg T.I.

Lucena Giraldo, Manuel (1988), "Ciencia para la frontera: las Expediciones de Límites españolas (1754-1804)”. En: Cuadernos Hispanoamericanos. Los Complementarios/2. Madrid.

(1991a), "Defensa del territorio y explotación forestal en Guayana, 17581793”. En: Lucena Giraldo, Manuel (Ed.), El bosque ilustrado. Estudios sobre la política forestal española en América. Madrid: ICONA e IIE. 
(1991b), Ilustrados y Bárbaros. Diario de la Expedición de Límites al Amazonas (1782), Madrid: Lucena Giraldo, Manuel (1988),Alianza-Quinto Centenario.

(1991c), Laboratorio tropical. La Expedición de Límites al Orinoco, 17501767, Caracas: Monte Avila Editores-Consejo Superior de Investigaciones Científicas.

(1992-1993), "Los jesuitas y la expedición de límites al Orinoco". En: Paramillo, San Cristóbal, 11-12.

(1997a), “Expedición de Límites de 1754-1761”, Diccionario de Historia de Venezuela. Caracas, Fundación Polar, II.

(1997b), “Iturriaga, José de”, Diccionario de Historia de Venezuela. Caracas, Fundación Polar, II.

(Ed.) (1999), Viajes a la Guayana ilustrada. El hombre y el territorio. Estudio introductorio, selección documental y notas de Manuel Lucena Giraldo, Caracas: Banco Provincia.

Martínez de la Escalera, José. “Cassani, José”. En: O’Neill, Charles E. y Domínguez, Joaquín $\mathrm{M}^{\mathrm{a}}$ (2001), Diccionario histórico de la Compañía de Jesús, RomaMadrid: Institutum Historicum S. I.-Universidad Pontificia de Comillas, I.

McNaspy, Clement J. y Domínguez, Joaquín María, En: O’Neill, Charles E. y Domínguez, Joaquín $\mathrm{M}^{\mathrm{a}}$ (2001), Diccionario histórico de la Compañía de Jesús, Roma-Madrid: Institutum Historicum S. I.-Universidad Pontificia de Comillas, II.

Meliá, SJ, Bartolomé (1967), “Quand les Indiens Guarani ont fait entendre leur voix... (Deux lettres inédites de 1753)”. En: Journal de la Société des Américanistes, $56 / 2$.

Mellinato, Giuseppe. “15. Retz, Francisco [Frantisek]”. En: O’Neill, Charles E. y Domínguez, Joaquín Ma (2001), Diccionario histórico de la Compañía de Jesús, Roma-Madrid: Institutum Historicum S. I.-Universidad Pontificia de Comillas, II.

“16. Visconti, Ignacio [Ignazio]”. En: O’Neill, Charles E. y Domínguez, Joaquín $\mathrm{M}^{\mathrm{a}}$ (2001), Diccionario histórico de la Compañía de Jesús, RomaMadrid: Institutum Historicum S. I.-Universidad Pontificia de Comillas, II.

Mémoires pour I'Histoire des Sciences et des beaux Arts, commencés d'etre imprimés l'an 1701 a Trevoux et dédiés a son Altesse Sérénissime Monseigneur le Prince Souverain de Dombes. A Paris. Chez Chabert : 1747, 1748, 1759.

Memorias de la Real Sociedad española de Historia natural, (1907), Tomo V: Homenaje a Linneo y Memoria $1^{\mathrm{a}}$, Madrid.

Moeller, Charles (1958), Literatura siglo XX y Cristianismo, Madrid: Edit. Gredos, IV.

Parra Pardi, María Elena (1997), “Solano y Bote, José”. En: Diccionario de Historia de Venezuela. Caracas, Fundación Polar, III.

Pelayo, Francisco y Puig-Samper, Miguel Ángel (1992), La obra científica de Löfling en Venezuela. Caracas, Cuadernos Lagovén. 
Pereira, Ricardo S. (1883), Documentos sobre Límites de los Estados Unidos de Colombia. Bogotá: Camacho Roldan y Tamayo.

Pérez Vila, Manuel (1997), “Garriga, Benito de la”. En: Diccionario de Historia de Venezuela. Caracas, Fundación Polar, II.

Pérez, Omar Alberto (1997), “Carreño, José Francisco”. En: Diccionario de Historia de Venezuela, Caracas: Fundación Polar, I.

Ponnad, Stanislaus (2001), “De Nobili, Roberto”. En: O’Neill, Charles E. y Domínguez, Joaquín $\mathrm{M}^{\mathrm{a}}$, Diccionario histórico de la Compañía de Jesús, Roma-Madrid: Institutum Historicum S. I.-Universidad Pontificia de Comillas, II.

Ramos Pérez, Demetrio (1988), Estudios de Historia venezolana, Caracas: Academia Nacional de la Historia.

(1997), “Alvarado, Eugenio de”. En: Diccionario de Historia de Venezuela, Caracas: Fundación Polar, I.

Ramos, Demetrio (1946), El tratado de límites de 1750 y la expedición de Iturriaga al Orinoco, Madrid: Consejo Superior de Investigaciones Científicas.

Riden, Stig (1957), Pedro Loefling en Venezuela, Madrid: Ínsula.

Sánchez Pérez, Joan-Eugeni (1991), Espacio, economía y sociedad, Madrid: Siglo XXI.

Santos Hernández, Ángel (1992), “Actividad misionera de los jesuitas en el continente americano”. En: Del Rey Fajardo SJ, José (Ed.), Misiones jesuíticas en la Orinoquia. San Cristóbal: Universidad Católica del Táchira, I.

Sebes, Joseph (2001) “Ricci, Mateo [Nombre chino: LI Madou]. En: O’Neill, Charles E. y Domínguez, Joaquín $\mathrm{M}^{\mathrm{a}}$ (2001), Diccionario histórico de la Compañía de Jesús, Roma-Madrid: Institutum Historicum S. I.-Universidad Pontificia de Comillas, IV.

Uriarte, José Eug. de y Lencina, Mariano (1929-1930), Biblioteca de escritores de la Compañía de Jesús pertenecientes a la antigua Asistencia de España, desde sus orígenes hasta el año de 1773, Madrid: Gráfica Universal, II.

Vega, Agustín de (2000), Noticia del principio y progresos del establecimiento de las Missiones de gentiles en la río Orinoco por la Compañía de Jesús, Estudio introductorio: José del Rey Fajardo sj y Daniel de Barandiarán, Caracas: Academia Nacional de la Historia. 